\title{
Investigation of the mixing layer height derived from ceilometer measurements in the Kathmandu Valley and implications for local air quality
}

\author{
Andrea Mues ${ }^{1}$, Maheswar Rupakheti ${ }^{1}$, Christoph Münkel ${ }^{2}$, Axel Lauer ${ }^{3}$, Heiko Bozem ${ }^{4}$, Peter Hoor ${ }^{4}$, Tim Butler ${ }^{1}$, \\ and Mark G. Lawrence ${ }^{1}$ \\ ${ }^{1}$ Institute for Advanced Sustainability Studies (IASS), 14467 Potsdam, Germany \\ ${ }^{2}$ Vaisala GmbH, 22607 Hamburg, Germany \\ ${ }^{3}$ Deutsches Zentrum für Luft- und Raumfahrt (DLR), Institut für Physik der Atmosphäre, Oberpfaffenhofen, Germany \\ ${ }^{4}$ Institute for Atmospheric Physics, Johannes Gutenberg University Mainz, Mainz, Germany
}

Correspondence to: Andrea Mues (andrea.mues@iass-potsdam.de) and Maheswar Rupakheti

(maheswar.rupakheti@iass-potsdam.de)

Received: 10 November 2016 - Discussion started: 6 January 2017

Revised: 12 April 2017 - Accepted: 18 May 2017 - Published: 4 July 2017

\begin{abstract}
In this study 1 year of ceilometer measurements taken in the Kathmandu Valley, Nepal, in the framework of the SusKat project (A Sustainable Atmosphere for the Kathmandu Valley) were analysed to investigate the diurnal variation of the mixing layer height (MLH) and its dependency on the meteorological conditions. In addition, the impact of the MLH on the temporal variation and the magnitude of the measured black carbon concentrations are analysed for each season. Based on the assumption that black carbon aerosols are vertically well mixed within the mixing layer and the finding that the mixing layer varies only little during night time and morning hours, black carbon emission fluxes are estimated for these hours and per month. Even though this method is relatively simple, it can give an observationally based first estimate of the black carbon emissions in this region, especially illuminating the seasonal cycle of the emission fluxes.

The monthly minimum median MLH values typically range between 150 and $200 \mathrm{~m}$ during night and early morning hours, the monthly maximum median values between $625 \mathrm{~m}$ in July and $1460 \mathrm{~m}$ in March. Seasonal differences are not only found in the absolute MLHs, but also in the duration of the typical daytime maximum ranging between 2 and $3 \mathrm{~h}$ in January and 6-7 h in May. During the monsoon season a diurnal cycle has been observed with the smallest amplitude (typically between 400 and $500 \mathrm{~m}$ ), with the lowest daytime
\end{abstract}

mixing height of all seasons (maximum monthly median values typically between 600 and $800 \mathrm{~m}$ ), and also the highest night-time and early morning mixing height of all seasons (minimum monthly median values typically between 200 and $220 \mathrm{~m}$ ). These characteristics can mainly be explained with the frequently present clouds and the associated reduction in incoming solar radiation and outgoing longwave radiation.

In general, the black carbon concentrations show a clear anticorrelation with MLH measurements, although this relation is less pronounced in the monsoon season. The daily evolution of the black carbon diurnal cycle differs between the seasons, partly due to the different meteorological conditions including the MLH. Other important reasons are the different main emission sources and their diurnal variations in the individual seasons. The estimation of the black carbon emission flux for the morning hours show a clear seasonal cycle with maximum values in December to April. Compared to the emission flux values provided by different emission databases for this region, the estimated values here are considerably higher. Several possible sources of uncertainty are considered, and even the absolute lower bound of the emissions based on our methodology is higher than in most emissions datasets, providing strong evidence that the black carbon emissions for this region have likely been underestimated in modelling studies thus far. 


\section{Introduction}

The project "A Sustainable Atmosphere for the Kathmandu Valley" (SusKat) (Rupakheti et al., 2017) initiated by the Institute for Advanced Sustainability Studies (IASS) and the International Centre for Integrated Mountain Development (ICIMOD) aims at a better understanding of the observed severe air pollution in the Kathmandu Valley and its surroundings. Adverse air quality is a major environmental and health concern in Nepal, especially in the urban areas of the Kathmandu Valley (Aryal et al., 2009; Panday and Prinn, 2009; Sharma et al., 2012). The rapidly expanding urban areas and the constantly increasing traffic volume in the Kathmandu Valley have resulted in a visible degradation of the air quality over the last decades. As part of the SusKat project the atmospheric characterisation campaign SusKat-ABC was conducted in Nepal from December 2012 through June 2013, during which a large number of chemical compounds and meteorological parameters were measured at several sites in the Kathmandu Valley and other parts of Nepal. The first measurement results highlight the severe air pollution and the need for a better understanding of the emissions and the meteorological and chemical processes resulting in such high pollution levels in the valley (e.g. Putero et al., 2015; Sarkar et al., 2016; Chen et al., 2016).

Geographically, Nepal stretches along the Great Himalaya Range and has a diverse topography. Nepal is one of the countries with the highest average elevation and is characterised by a steep north-south gradient in surface elevation. The Kathmandu Valley is a bowl-shaped elevated basin at an altitude of $1300 \mathrm{~m}$ a.s.l. It has a nearly flat bottom with an area of $340 \mathrm{~km}^{2}$. The valley is surrounded by mountain ridges ranging between 2000 and $2800 \mathrm{~m}$ a.s.l. with five passes (200-1500 $\mathrm{m}$ above valley floor) and a river outlet. The valley is particularly vulnerable to air pollution because of its bowl-shaped topography which restricts air flow and ventilation of pollutants. The meteorology of Nepal is dominated by the Asian monsoon circulation. The basics of the monsoon meteorology are similar each year but the exact timing of the beginning and the end of the individual monsoon periods vary each year. The yearly cycle can be broken down into four basic seasons: the pre-monsoon season (March, April and May), the monsoon (June, July, August and September), the dry or post-monsoon season (October, November) and the winter season (December, January and February) (e.g. Shrestha et al., 2000). The valley's meteorology is influenced by both large-scale synoptic features and the local mountain valley circulation. Typically, the valley receives up to $90 \%$ of its annual precipitation during the monsoon months in summer.

For local air quality the so-called planetary boundary layer (PBL) is of key importance. This layer is directly affected by the underlying surface and responds to surface forcing (e.g. friction, heat transport and emission of pollutants) with a timescale of about an hour or less (Stull, 1988). The thick- ness of the PBL varies in time and space. The structure of the PBL has important implications for air quality as most air pollutants are emitted into this layer, are transported horizontally and vertically and affect people and the environment there. For these reasons it is particularly valuable to have information on the vertical structure and characteristics of the PBL. In general, the structure of the PBL can be divided into different (sub-) layers according to their thermodynamic characteristics. A key parameter for air quality is the vertical depth of the so-called mixing layer (ML). The top of the ML is characterised by a strong gradient in parameters such as aerosol concentration. The top of the ML has a distinct diurnal cycle that depends on both the synoptic and local weather conditions as well as the local topography. The ML is often characterised by an unstable layer and strong mixing due to turbulence, mainly convection, during the day (convective mixing layer). The ML during daytime is separated from the free atmosphere by an entrainment zone, a stable layer which prevents the transport of, for example, air pollutants from the ML into the free atmosphere. During the night a stable layer (also called the stable boundary layer) develops upwards from the ground, capped by a residual layer. This stable boundary layer is characterised by stable stratification with weak and sporadic turbulence and low mixing. In the case of cloudy and rainy conditions the diurnal evolution of the ML is less pronounced resulting in a lower extent of this layer (Stull, 1988).

In spite of its importance there are only indirect methods to determine the mixing layer height (MLH) from measurements taken by remote sensing or radio soundings (e.g. Emeis et al., 2008, 2012; Eresmaa et al., 2006; Ketterer et al., 2014; Wiegner et al., 2014; Singh et al., 2016). To our knowledge only limited studies are available on the PBL evolution over the complex terrain of the Himalayan region and specifically the Kathmandu Valley. Singh et al. (2016) investigated the time evolution of the local boundary layer (LBL) using a radar wind profiler over a mountain ridge at Nainital (India) in the central Himalayan region from November 2011 to March 2012. Their results revealed a pronounced impact of mountain topography on the local boundary layer dynamics in March when strong winds resulting in strong orographic lifting over the site lead to night-time LBL heights considerably larger than during November to February. Shrestha et al. (2015) present results for the MLH derived from sodar (Doppler sonic detection and ranging system) measurements for the time period 11 to 24 June 2013 at a site located at a western low-mountain pass in the Kathmandu Valley. The main findings are that this pass channels regional air masses from outside the valley up into the Kathmandu Valley as westerly northwesterly wind during daytime, whereas air masses are drained through the pass out of the valley during night time. They also presented a comparison of the diurnal variation of the MLH at this station and a station in the central part of the valley. The analysis strongly suggests that the air mass flowing into the Kathmandu Valley through this pass 
is a cool density flow over the weakly stratified mixed layer of the valley. Regmi et al. (2003) describe similar results analysing sodar measurements (6 to 12 April 2001) taken in the centre of the Kathmandu Valley along with model simulations to study the late wintertime local flows of the valley. The simulations showed that two characteristic local flows tend to enter the valley in the afternoon through the mountain gaps surrounding the Kathmandu Valley - southwesterly from the Indo-Gangetic Plain and northwesterly from the valley westward. These cool wind layers meet at the centre of the valley and form a double-layering structure there. The lower layer is shallow, being composed of the cooler southwesterly air mass from the Indo-Gangetic Plain. It was concluded that this local flow structure suppresses vertical mixing and leads to high air pollution by decreasing the daytime ventilation of air masses in the valley (Regmi et al., 2003).

A ceilometer was deployed to measure vertical profiles of the aerosol attenuated backscattering during the SusKatABC campaign at Bode, the supersite of the SusKat-ABC campaign, located in a semi-urban setting in the Kathmandu Valley (more details are presented in Sect. 2.2). These measurements are used to determine the height of the ML. To our knowledge these data are the first multi-year ceilometer measurements in the Kathmandu Valley, and in the greater Nepal region, and provide a unique dataset for the analysis of the meteorological conditions and the air quality in this region.

The main aim of setting up the ceilometer instrument as part of the measurement campaign was to better understand the atmospheric dynamics in the valley and to thereby support the analysis of the air pollutant measurements. In this study the MLH data were used to analyse the diurnal variation of the MLH for each season and its dependency on the meteorological conditions and they provide information on the relation between air pollution concentration and the ML. As an example of such relationships, black carbon (BC) measurements simultaneously measured at the Bode site are analysed and presented. BC is chosen because it has a very low chemical reactivity in the atmosphere and can thus be seen as a tracer for air pollution. Its primary removal process is wet or dry deposition (e.g. Bond et al., 2013).

The analysis presented in this study focuses on the impact of the diurnal variation of the MLH on the temporal variation and the magnitude of the BC concentration for each season of the year. This also allows for an assessment of the impact of the MLH on air pollutant concentrations compared to other processes such as the amount and the timing of emissions, horizontal advection and deposition. Furthermore, the information on the diurnal cycle of the MLH and the BC concentration were used to estimate the $\mathrm{BC}$ emission flux in the morning hours for each month.

\section{Method}

\subsection{The SusKat-ABC measurement campaign}

A central part of the SusKat project is a 7-month-long (December 2012 to June 2013) field campaign (SusKat-ABC) with a 2-month-long intensive campaign (December 2012 to February 2013) in Nepal with a focus on the Kathmandu Valley providing detailed observations of a large number of chemical compounds and meteorological parameters ( $\mathrm{Ru}-$ pakheti et al., 2017). The name SusKat-ABC refers to the collaboration with the Atmospheric Brown Cloud (ABC) Programme of the United Nations Environment Programme (UNEP), which provided access to a wide network of researchers in Asia who conducted measurements during the campaign. From December 2012 to June 2013, more than 40 scientists from nine countries representing 18 research groups deployed more than 160 state-of-the-art scientific measurement instruments for intensive ground-based monitoring. The measurement network includes one urban supersite and five satellite stations within and on the rim of the Kathmandu Valley, and five regional sites in the broader region surrounding the Kathmandu Valley and other parts of Nepal. Some of the instruments deployed in the Kathmandu Valley continued to measure beyond the SusKat-ABC campaign and thus collected long-term data that provided a first opportunity for analysis of long-term characteristics of air pollution and meteorology.

In this study the measurements with a Vaisala ceilometer (CL31, Finland) (Münkel, 2007) are used to study the vertical structure of the atmosphere, especially the MLH. To cover a whole annual cycle, data from March 2013 to February 2014 are used here. The report interval of the CL31 is every $2 \mathrm{~min}$ with a vertical range resolution of $20 \mathrm{~m}$. From that aerosol layer heights are calculated for every $10 \mathrm{~min}$ and MLHs for every hour according to the description in Sect. 2.2. In addition to the ceilometer data also solar radiation, wind, precipitation and BC measurements are used in this study. The meteorological parameters were measured with an automatic weather station (Campbell Scientific, UK) with the CS215 sensor for humidity and temperature, the CS300 pyranometer for global radiation, and the RM Young 05103-5 wind vane to measure wind speed and direction. Global solar radiation observations were taken with an instrument measuring total sun and sky solar radiation. Its spectral range of 360 to $1120 \mathrm{~nm}$ encompasses most of the shortwave radiation that reaches the Earth's surface. The sensors were kept $2 \mathrm{~m}$ above the surface of the roof of a building ( $15 \mathrm{~m}$ above the ground). The meteorological data were recorded every minute.

The BC concentrations were measured by an Aethalometer, model "AE33" (Magee Scientific, USA). This particular model is a dual-spot measurement for loading correction (Drinovec et al., 2015). The Aethalometer is among the earliest BC measurement methods and has been applied since the early 1980s (e.g. Hansen et al., 1982, 1984). This mea- 


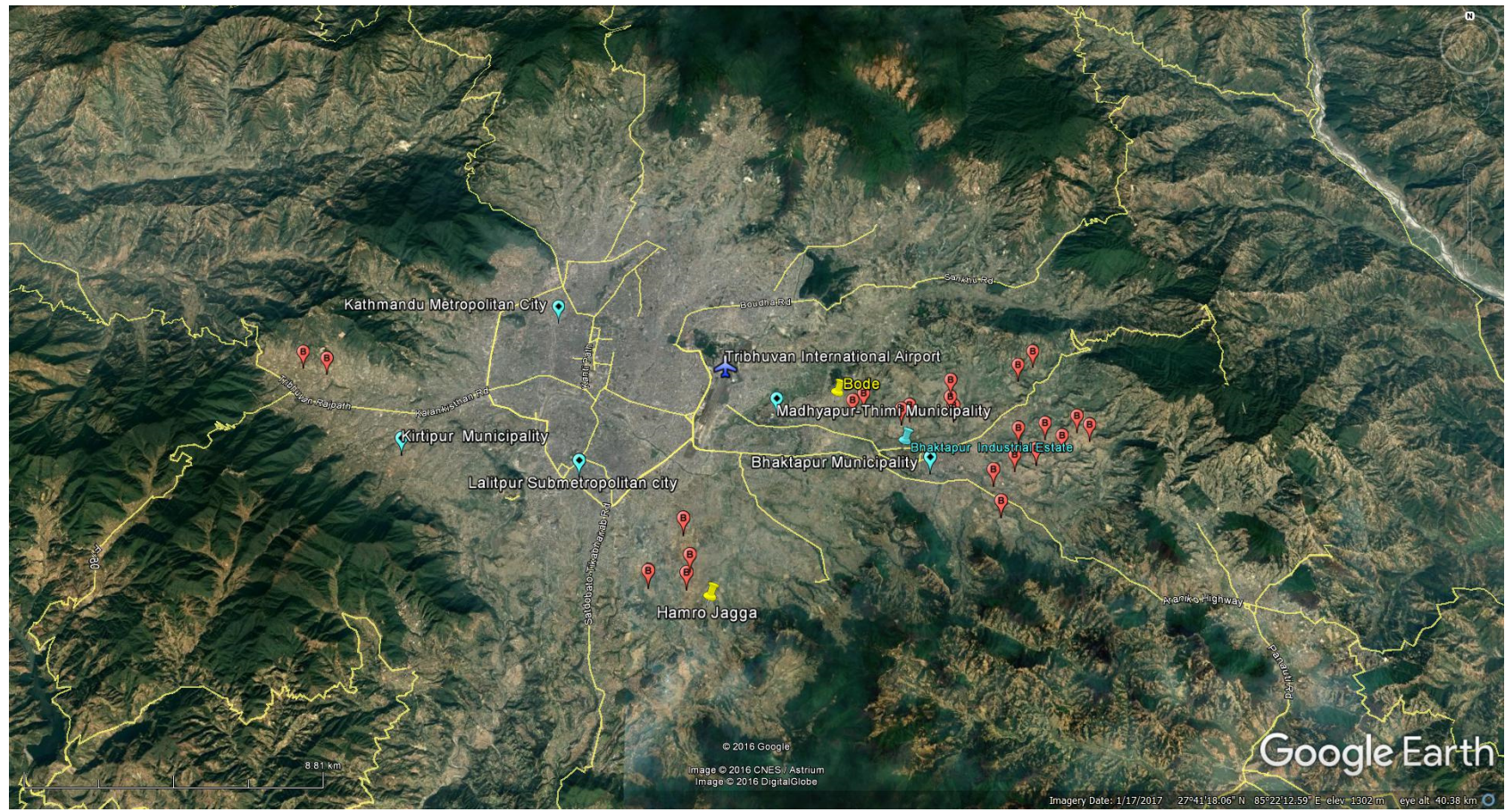

Figure 1. Location of the measurement site Bode and the five major cities in Kathmandu Valley: Kathmandu, Lalitpur, Bhaktapur, Kirtipur and Madhyapur-Thimi. The major roads are highlighted, clusters of brick kilns are marked (B). Google Earth, 2016; @2016 Google, image(C 2016 CNES/Astrium, image $@ 2016$ DigitalGlobe.

surement is a filter-based method where air is drawn through a sampling filter and an increase in attenuation is detected with increasing aerosol loading on the filter. Its advantage is that it provides an absorption-derived real-time estimate of BC. However, the instrument measures absorption coefficient by all components of the aerosol besides $\mathrm{BC}$ over the broad region of the spectrum. It requires therefore knowledge of the mass specific absorption cross section (MAC) of the BC-containing aerosol, which introduces some uncertainty to the measured values. The derived quantity is commonly referred to as "equivalent black carbon" (EBC), which is the case if the MAC is exactly known (see, e.g., Petzold et al., 2013). The AE33 deployed in Bode was fully factory calibrated before commencing the field campaign. In Bode, the AE33 was set to measure aerosol absorption at a time resolution of $1 \mathrm{~min}$ time average and the sample flow was set at local volumetric flow of $5 \mathrm{~L} \mathrm{~min}^{-1}$. The tape advance was based on an attenuation of 120 and each tape advance was followed by clean air test. The clean air test was also performed whenever a new tape was inserted in the Aethalometer. The AE33 is designed for a fairly automated and continuous measurement. Some of the operational issues during the field campaign include the change of the bypass filter cartridge, which was replaced whenever the clean air test failed or when the colour of the filter inside the cartridge changed from white to grey or dark. Additionally, the optical chamber was also cleaned in response to the failure of the clean air test. The analysis presented in the paper is based on the $1 \mathrm{~min}$ average data collected at Bode. Post-processing of the collected data includes flagging and averaging to $1 \mathrm{~h}$ values. The $1 \mathrm{~min}$ data were flagged based on operational parameters of the instrument such as status, flow ratio and tape advance. In addition, the time series of $\mathrm{BC}$ was plotted against data from other co-located particle mass, number and trace gas concentrations to identify noise or influence of nearby sources. The contributions of nearby sources were identified by "short-duration (1-3 min) spikes" in the time series, also indicated by other co-located instruments. The flags were applied to $1 \mathrm{~min}$ data, and the flagged data were averaged to $1 \mathrm{~h}$ values. The averaging only considered time periods with at least $75 \%$ (of $1 \mathrm{~min}$ ) data points available as valid $1 \mathrm{~h}$ values.

To cover a whole annual cycle, data from March 2013 to February 2014 are used here. All data are used with a time resolution of $1 \mathrm{~h}$ calculated as a mean from the original data. All instruments were located at the Bode site (Fig. 1) in the Kathmandu Valley and kept $2 \mathrm{~m}$ above the surface of the roof of a building about $15 \mathrm{~m}$ above ground. The surroundings of the measurement site are characterised by a mixed residential and agricultural setting in a suburban location with only light traffic and less densely scattered buildings than in the centre of the Kathmandu Valley. An overview on the availability of the MLH and the BC data used in this study is given in Table 1. The availability of the MLH data per hour varies between the four seasons (70 to $93 \%$, Table 1). Least 
Table 1. Overview on the availability of the hourly MLH and BC data for four seasons during the period March 2013 to February 2014.

\begin{tabular}{lrrrrr}
\hline Season 2013/2014 & Total data & MLH data & MLH data only dry days & BC data & BC data only dry days \\
\hline Mar-May 2013 & 2208 & $1579(72 \%)$ & $1106(50 \%)$ & $2138(97 \%)$ & $1517(69 \%)$ \\
Jun-Sep 2013 & 2928 & $2052(70 \%)$ & $716(24 \%)$ & $2155(74 \%)$ & $705(24 \%)$ \\
Oct-Nov 2013 & 1464 & $1218(83 \%)$ & $1143(78 \%)$ & $1345(92 \%)$ & $1212(83 \%)$ \\
Dec 2013-Feb 2014 & 2160 & $2010(93 \%)$ & $1925(89 \%)$ & $1615(75 \%)$ & $1508(70 \%)$ \\
\hline
\end{tabular}

data are available in the monsoon season which is likely due to a more frequent occurrence of clouds, fog and precipitation in this season, as the BL-VIEW algorithm excludes profiles with fog, precipitation or low clouds. We consider a data availability of $70 \%$ as sufficient for our analysis.

\subsection{Ceilometer measurements and analytical methods}

Ceilometers are routinely used for automatic reports of the MLH. Numerous studies (e.g. Emeis et al., 2008; Eresmaa et al., 2006; Helmis et al., 2012) show that ceilometer data are suitable for studying the vertical characteristics of the atmosphere and for using the obtained profiles to assess the height of aerosol layers and the MLH. Haeffelin et al. (2012) discuss the most common methods for mixing height determination with ceilometers; these include gradient methods investigating first or second derivative of the backscatter profile reported by the instrument, backscatter variance, wavelet and backscatter profile covariance, and fitting of ideal backscatter profiles. All methods involve temporal averaging ranging from 2 to $60 \mathrm{~min}$, depending on the atmospheric conditions and the performance of the instrument. Other techniques used to determine the MLH such as sodar (sound detecting and ranging) or radiosonde measurements show a good agreement with results from ceilometer data also in mountain areas (Ketterer et al., 2014). In Münkel et al. (2011) measurements taken with eye-safe Vaisala ceilometers of the same kind as in the SusKat project were treated with the same algorithm (Vaisala BL-VIEW) to determine the MLH as used in this study. In particular, Münkel et al. (2011) compare the MLHs obtained during the Tall Wind measurement campaign in Hamburg, Germany, and routine measurements carried out in Vantaa, Finland, with MLHs derived from potential temperature and relative humidity profiles reported by radio soundings. The example cases presented in the study show a good agreement with deviations not exceeding $10 \%$.

The ceilometer CL31 used in this study employs pulsed diode laser lidar (light detection and ranging) technology, where short laser pulses are sent out in a vertical or nearvertical direction. The operating principle of the ceilometer is based on the measurement of the time needed for the short laser impulse to traverse the atmosphere from the transmitter of the ceilometer to a backscattering volume, e.g. fog, mist, precipitation, clouds, and back to the receiver of the ceilometer. Knowing the speed of light, the time delay between the launch of the laser pulse and the detection of the backscatter signal indicates the cloud base height. The ceilometer CL31 is able to detect three cloud layers simultaneously. Because the laser light is attenuated by atmospheric particles on its way to the backscattering volume and back to the ceilometer the profile is better called "attenuated backscatter". Prior to transmission, the received signal is multiplied by the square of the distance to the backscattering volume and divided by the overlap factor, which accounts for the fraction of the light cone of the transmitter that is within the field-of-view of the receiver. This procedure ensures the comparability of the signal received from different distances - for details see, for example, Kotthaus et al. (2016).

From the attenuated backscatter profiles, data points with observed clouds, fog or precipitation within the ML are excluded from the analysis. Therefore the degree of signal attenuation is so low that the attenuated backscatter profile can be used as a proxy for the aerosol density in the observed backscattering volume. The criterion excludes data points with (i) clouds or fog, i.e. cloud bases or vertical visibility below $160 \mathrm{~m}$, and with (ii) precipitation, i.e. cloud layers below $4000 \mathrm{~m}$ and an attenuated backscatter signal of at least $2 \times 10^{-6} \mathrm{~m}^{-1} \mathrm{sr}^{-1}$ in the height range $0 \mathrm{~m}-$ minimum (cloud base, $1000 \mathrm{~m}$ ). The algorithm used to determine the aerosol density and MLH from ceilometer data collected in the Kathmandu Valley is the Vaisala BL-VIEW algorithm version 1.1, which has been slightly adapted according to the instrument settings used in this study. It has been introduced in Münkel and Roininen (2010) and is a part of the commercial Vaisala software product BL-VIEW. This algorithm is based on the gradient method looking for the gradient minima in the attenuated backscatter profiles that mark the top of aerosol layers (Münkel, 2007). This is based on the assumption that within the ML the aerosol concentration is nearly constant in the vertical and distinctly higher than above (Steyn et al., 1999).

In addition to the attenuated backscatter, every profile contains a considerable amount of noise that is generated by the receiver electronics and stray daylight. Because for single profiles, this noise can outweigh all atmospheric structures, a profile correction is necessary. Thus a vertical and temporal averaging procedure is applied to avoid a detection of false layers generated by signal noise. The amount of signal noise depends on the range and time of the day; thus, the enhanced gradient method introduces variable averaging parameters. Long averaging intervals help to prevent false gradient minima hits generated by signal noise. On the other 


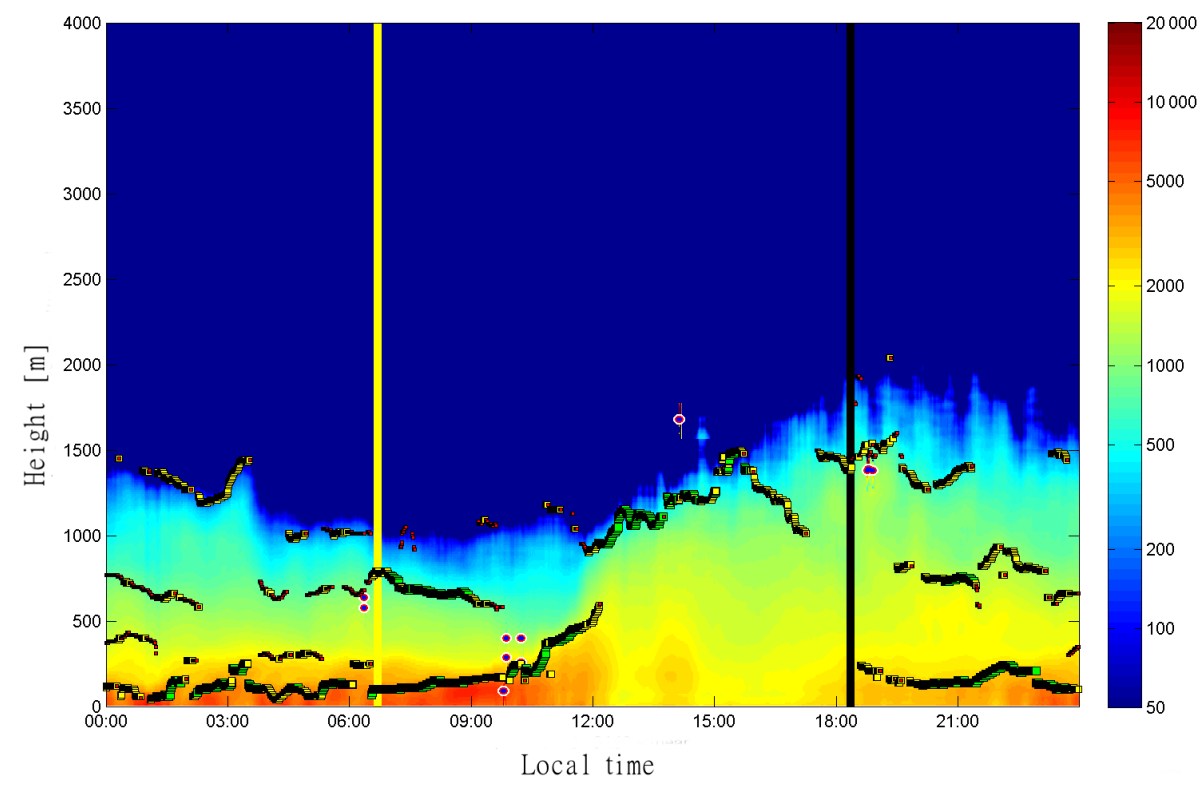

Figure 2. Attenuated backscatter density measured on 9 March $2014\left(10^{-9} \mathrm{~m}^{-1} \mathrm{sr}^{-1}\right)$ together with the aerosol layers reported by BL-VIEW (rectangles) and cloud bases reported by the ceilometer (blue and red circles). The yellow and black vertical lines indicate sunrise and sunset.

hand, this approach reduces the ability of the algorithm to respond to short-scale signal fluctuations in space and time. For noise detection the far range between 6200 and $7200 \mathrm{~m}$ is investigated for every profile reported by the ceilometer. This far-range profile contains $30 \mathrm{~s}$ average data. Two values are calculated for each profile in order to minimise the influence of high cloud signal: standard deviation of the profile values between 6200 and $6700 \mathrm{~m}$, and standard deviation of the profile values between 6700 and $7200 \mathrm{~m}$. The minimum of those values is the noise value used to determine the averaging time interval. In the SusKat project the time averaging interval for the backscatter signal is 15 to 52 min depending on the signal noise. The choice of the intervals used for averaging over height is independent of noise; to account for the noise amplification introduced by the range squared multiplication, the sliding averaging intervals rise gradually from $80 \mathrm{~m}$ for all $10 \mathrm{~m}$ height bins below 200 to $360 \mathrm{~m}$ for all $10 \mathrm{~m}$ height bins above $1500 \mathrm{~m}$. Example: the attenuated backscatter value at $100 \mathrm{~m}$ height is replaced with the average of the values between 60 and $140 \mathrm{~m}$. Not all gradient minima are reported by the BL-VIEW algorithm; both signal and gradient have to exceed threshold values that are a function of signal noise. Especially during daytime situations with small aerosol load, aerosol layer reports are often not available. An aerosol layer is reported if a minimum threshold of $200 \times 10^{-9} \mathrm{~m}^{-1} \mathrm{sr}^{-1}$ is exceeded in the attenuated backscatter signal. Small density fluctuations within a convective boundary layer with a high aerosol load can lead to low gradient values which could be reported as the top of the aerosol layer. To prevent the report of these fluctuations as the top of the aerosol layer, variable threshold values for the signal and gradient are introduced.
For the evaluation in the frame of the SusKat project, the height of the lowest detected aerosol layer was regarded as the MLH and the nocturnal stable boundary layer, respectively. Figure 2 shows the colour-coded attenuated backscatter profile averaged following the procedure explained above for $24 \mathrm{~h}$ together with the aerosol layers reported by BLVIEW (rectangles) and cloud bases reported by the ceilometer (blue and red circles). The yellow and black vertical lines indicate sunrise and sunset. Only from 13:00 to 21:00 local time does the MLH exceed $500 \mathrm{~m}$; during the rest of the day it barely exceeds $100 \mathrm{~m}$. BL-VIEW reports up to three aerosol layer heights every $10 \mathrm{~min}$. In the scope of the SusKat project, a more convenient time base for comparison with air quality and meteorological parameters is $1 \mathrm{~h}$. Therefore for every hour the last six reported $10 \mathrm{~min}$ values are examined to find the most applicable value to represent all $10 \mathrm{~min} \mathrm{MLH}$ values of the last hour. For this purpose a weighing procedure is applied to find the height value with most hits in its vicinity. As part of this weighing procedure a score $S\left(\mathrm{MLH} t_{x}\right)$ for every $10 \mathrm{~min}$ value per hour $\left(t_{x}\right)$ is calculated and the reported $10 \mathrm{~min}$ MLH with the highest score gets reported as the MLH of this particular hour. For the calculation of the score $S\left(\mathrm{MLH} t_{x}\right)$ of the $10 \mathrm{~min}$ MLH at time $t_{x}$ only the 10 min values per hour (MLHi, $i=1$ to 6 with |MLHi $\mathrm{MLHt}_{x} \mid<200 \mathrm{~m}$ ) are taken into account which are within a distance of less than $200 \mathrm{~m}$ from the height value $\mathrm{MLH}_{x}$ :

$$
\begin{aligned}
& S\left(\mathrm{MLH} t_{x}\right) \\
& =\sum_{\mathrm{MLH} t_{x}-200<\mathrm{MLH} i<\mathrm{MLH} t_{x}+200} 1-\frac{\left|\mathrm{MLH} i-\mathrm{MLH} t_{x}\right|}{200} .
\end{aligned}
$$



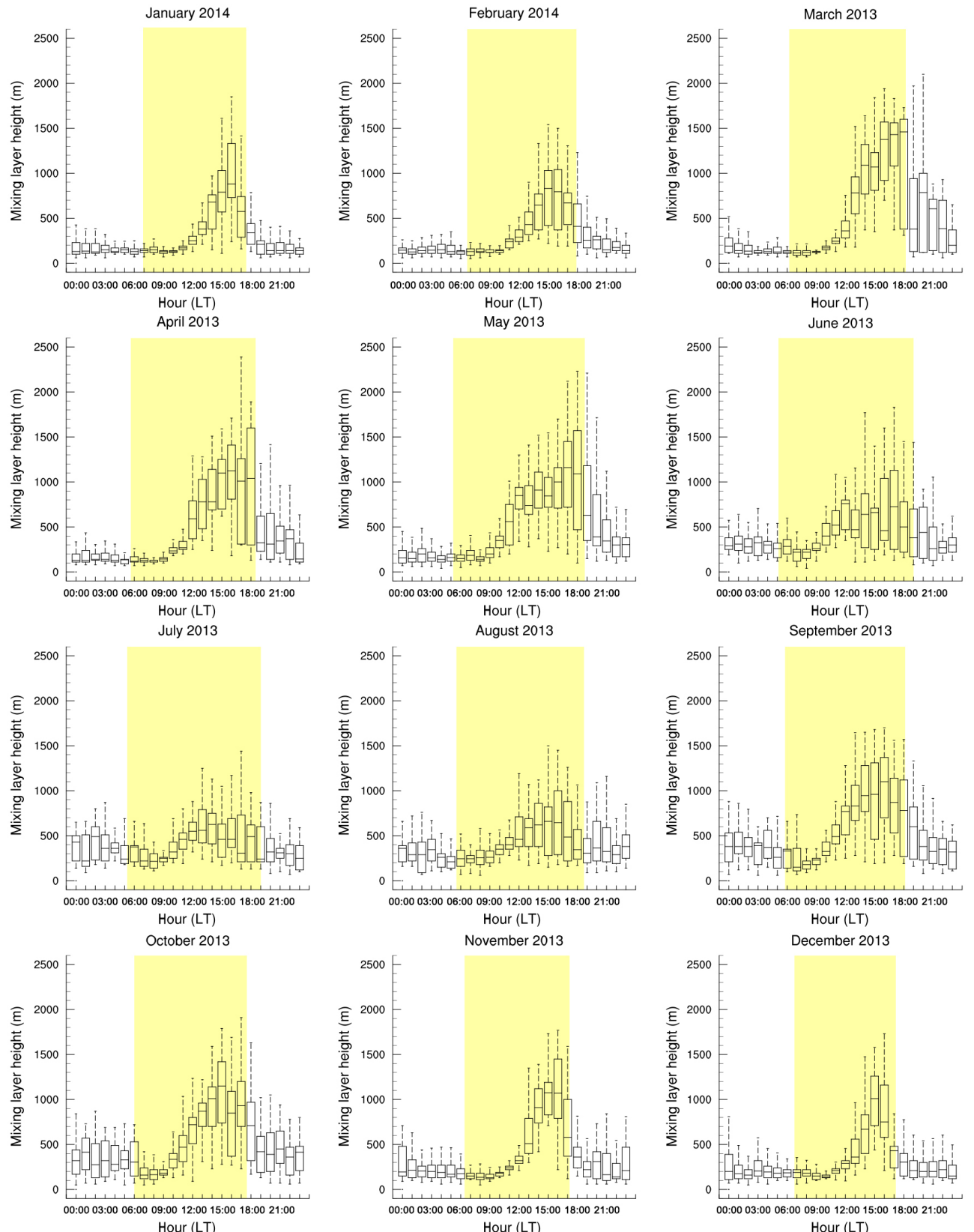

Figure 3. Monthly diurnal cycle of the MLH as box-and-whisker plots (showing the median, the upper and lower quantile and whisker) at the Bode site in the time period March 2013 to February 2014: (top left) January 2014) to (bottom right) December 2013. The yellow shading indicates the daylight periods on the 15 th of each month.

The lowest of the height values MLH $t_{x}$ with highest score $S\left(\mathrm{MLH} t_{x}\right)$ is reported as MLH presenting best all detections within the past hour. To some extent it resembles a median calculation, but the $200 \mathrm{~m}$ distance restriction avoids unrealistic results in two-layer situations like this: if 310 , $330,250,600,620$, and $620 \mathrm{~m}$ are the 10 min values, then $S(310 \mathrm{~m})=2.6, S(600 \mathrm{~m})=2.8, S(620 \mathrm{~m})=2.9$, and $620 \mathrm{~m}$ get reported.
The ceilometer deployed in the Kathmandu Valley is a "first-generation" ceilometer (CL31). The settings fitting best for the MLH assessment with the CL31 are $16 \mathrm{~s}$ report interval and $10 \mathrm{~m}$ height resolution because the CL31 internal memory stores only up to $16 \mathrm{~s}$ accumulation time. These recommended settings provide the best possible signal-to-noise ratio with the minimum required data flow. During the time period investigated in this study, it had not been operated with settings fitting best for MLH assessment. For exam- 
ple, the report interval was set to $120 \mathrm{~s}$ instead of $16 \mathrm{~s}$. Before applying the algorithm to determine the MLH, the attenuated backscatter range has to be converted to attenuated backscatter height with $10 \mathrm{~m}$ height resolution. Tilting angle and range resolution is taken into account for this. Here a range resolution of $20 \mathrm{~m}$ instead of $10 \mathrm{~m}$ was chosen. Nevertheless, most of the time the aerosol load in the Kathmandu Valley was still sufficiently high for reliable MLH retrievals. See Kotthaus et al. (2016) for a more detailed discussion of the influence of CL31 hardware and firmware versions on the backscatter profiles.

\section{Results}

\subsection{Seasonal variation of the diurnal cycle of the MLH}

The diurnal cycle of the MLH is typically characterised by low MLHs during the night, gradually increasing after sun rise and reaching maximum values in the afternoon before decreasing again later in the day (Fig. 3). Seasonal differences can be seen particularly in the duration of enhanced MLHs during daytime and in the measured minima and maxima. Sunrise varies between about 05:00 and 07:00 during the year with times between about 05:00 and 06:30 in the pre-monsoon season, 05:00 and 06:00 in the monsoon season, 05:10 and 05:50 in the post-monsoon season and 06:30 and 07:00 in the winter season. The day length during a year varies between about 10.5 and $14 \mathrm{~h}$, with 11.5 to $13.75 \mathrm{~h}$ in the pre-monsoon season, 12 to $14 \mathrm{~h}$ in the monsoon season, 10.5 to $11.8 \mathrm{~h}$ in the post-monsoon season and 10.5 to $11.5 \mathrm{~h}$ in the winter season. In the pre-monsoon season (March-May, Fig. 3) the diurnal cycle is very distinct with a low ML in the night and morning hours (median around $130 \mathrm{~m}$ ) and an increase of the height from about 10:00 to a maximum between 16:00 and 18:00. After 18:00 the MLH decreases rapidly and the values of the median MLH drop from $1130 \mathrm{~m}$ down to $470 \mathrm{~m}$, indicating the development of a stable layer from the surface upwards after sunset. The maximum MLHs measured during the pre-monsoon season are in general the highest of all seasons (maximum median value at 17:00 of $1210 \mathrm{~m}$ ). In contrast to the premonsoon season the amplitude of the diurnal cycle measured during the monsoon season (June-September) is much less distinct, with the lowest differences of all seasons between the minimum and maximum of the cycle (maximum difference of medians: $480 \mathrm{~m}$ ). Furthermore, among all seasons, the lowest MLH during the day (maximum median $700 \mathrm{~m}$ ) and the highest during the night and morning hours (median $220-370 \mathrm{~m}$ ) is observed in this season. In the post-monsoon season (October-November) the MLH during the night and morning hours is still high with a median of 150 to $290 \mathrm{~m}$ compared to the pre-monsoon season and the maximum is shifted to earlier hours (around 15:00). The diurnal cycle in winter (December-February) shows a low ML in the morn- ing and night hours with a median of around $150 \mathrm{~m}$. It is also characterised by a short duration of enhanced MLHs during daytime (around $8 \mathrm{~h}$ ) with maximum heights of on average less than $900 \mathrm{~m}$. The same characteristics are shown by the data for the year 2014 (not shown here) which strongly suggests that the diurnal cycles discussed above are quite typical for the particular seasons in that region.

\subsection{MLH and meteorology}

The development and characteristics of the ML depend to a large extent on the local meteorological characteristics in the region. Because of their high impact on the development of the ML, also measurements for solar radiation, wind speed and precipitation at the Bode station are shown in this analysis.

To a large degree, the characteristics of the diurnal cycle of the MLH as described in Sect. 3.1 are consistent with the characteristics of the diurnal cycle of these meteorological parameters. As a key driving force for convection, solar radiation has a strong impact on the development of the ML and thus, both diurnal cycles show in general similar structures (Fig. 4). The maximum of the MLH, however, is shifted a couple of hours towards the late afternoon compared to the maximum in solar radiation. This is due to the growth process of the ML, which is driven by the heating of the ground by incoming solar radiation. This heating causes thermals to rise from the surface layer, causing mixing when they overshoot into the more stable free troposphere at the entrainment layer, which in turn results in growth of the ML by gradual assimilation of overlying free tropospheric air which is forced down into the ML throughout the day. Because it takes time for the mixed layer to grow by this process, and also because the increase in the surface ground temperature lags behind the increase in incoming solar radiation during the morning, the peak in the MLH is in the late afternoon, as contrasted with the noon peak in incoming solar radiation. In addition to convection also the occurrence of mechanical turbulence in the PBL, indicated by the wind speed (Fig. 5), has an impact on the formation of the MLH. In all seasons the measured wind speeds are typically low with a maximum of less than $6 \mathrm{~m} \mathrm{~s}^{-1}$. During night time the wind speed in all seasons is typically below $1 \mathrm{~m} \mathrm{~s}^{-1}$, which indicates, together with the very low mixing height in the pre-monsoon and winter season, very stable conditions with only low vertical mixing during the night and morning hours.

The seasonal characteristics of the MLH diurnal cycle are also reflected in the seasonal cycles of the meteorological parameters. The highest daily maximum ML is measured in the pre-monsoon season when also the solar radiation is the strongest (maximum median $1210 \mathrm{~m}, 828 \mathrm{~W} \mathrm{~m}^{-2}$ ) (Fig. 4a), whereas both are lowest in the winter season (maximum median $830 \mathrm{~m}, 582 \mathrm{~W} \mathrm{~m}^{-2}$ ) (Fig. 4d). The diurnal cycle of the MLH for the monsoon season was found to be slightly different from the other seasons. This is also observed in the 
(a)

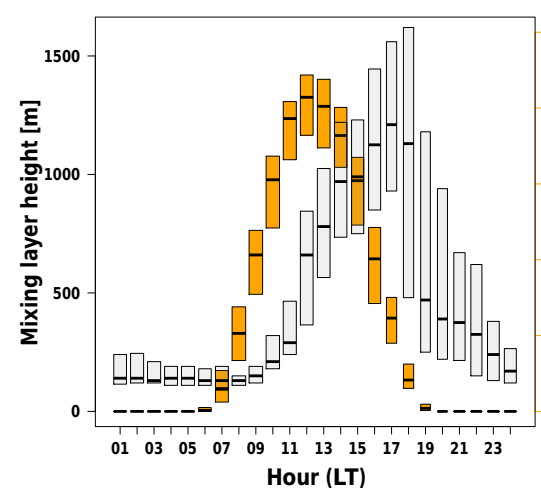

(c) Post-monsoon season

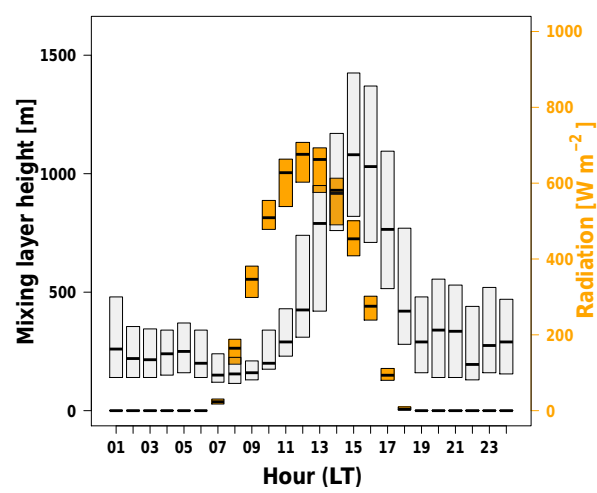

(b)

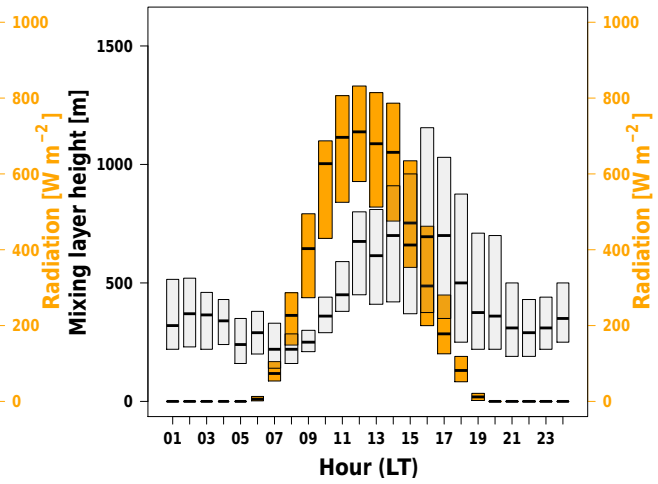

(d) Winter season

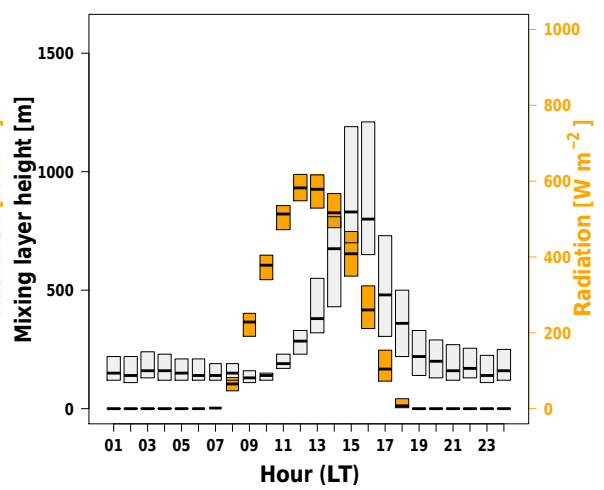

Figure 4. Diurnal cycle of the MLH (grey) and solar radiation at the surface (orange) as a boxplot (showing the median, the upper and lower quantile) for (a) the pre-monsoon (March-May 2013), (b) the monsoon (June-September 2013), (c) the post-monsoon (October-November 2013) and (d) the winter (December 2013-February 2014) season at the Bode site.

diurnal cycles of solar radiation and wind speed. The diurnal cycle of the solar radiation shows a larger range of values per hour of the day given by, for instance, the 25 th and 75 th percentiles (Fig. 4b) than in the other seasons. This indicates transition from clear sky conditions to a cloudy regime and the impact of the more frequent occurrence of cloud layers during this season leading to lower solar radiation values. The consequential reduction in energy leads to a reduced formation of turbulence and thus to lower MLHs. This can also be seen when comparing the diurnal cycle averaged over all days (grey) with the cycle obtained when averaging only over days with precipitation not exceeding a sum of $0.5 \mathrm{~mm}$ per day (dry days) (light orange) in Fig. 6. When extracting the MLH from the ceilometer measurements all hours with clouds or precipitation were not taken into account, in contrast to that using only "dry days" means that the whole day with a sum of precipitation exceeding $0.5 \mathrm{~mm}$ is omitted. Only $24 \%$ of the whole dataset of MLH is considered in the calculation of the diurnal cycle for dry days in the monsoon season (Table 1). Figure 6 therefore illustrates the impact of rainy days and the shielding of solar radiation by the associated clouds on the height of the ML in the monsoon season. Compared to the diurnal cycle of the MLH for all days, the diurnal cycle for "dry days" is more distinct and shows a much higher maximum MLH during daytime (difference of max. median around $240 \mathrm{~m}$ ). This difference between dry and all-day MLHs is much smaller in the other seasons. The sum of precipitation per day is used here as a proxy for the cloud amount to study the impact of days with a large fraction of cloud amount on the MLH. Therefore the presence of clouds in the monsoon season explains a large part of the on average lower MLH and higher variability compared with other seasons.

The described differences in the MLH between the seasons during night time are consistent with the seasonal variation of the surface temperature and the heat capacity of the soil. Higher average surface temperatures in the monsoon and post-monsoon seasons lead to higher MLHs during the night compared with pre-monsoon and winter conditions. Another potential reason is the presence of clouds during the night, especially in the monsoon season, which reduces the outgoing longwave radiation and thus the related radiative cooling of the surface.

In addition to the impact of the meteorology on the formation of the mixing layer in mountain regions, the topography and in this case more specifically the structure of the 

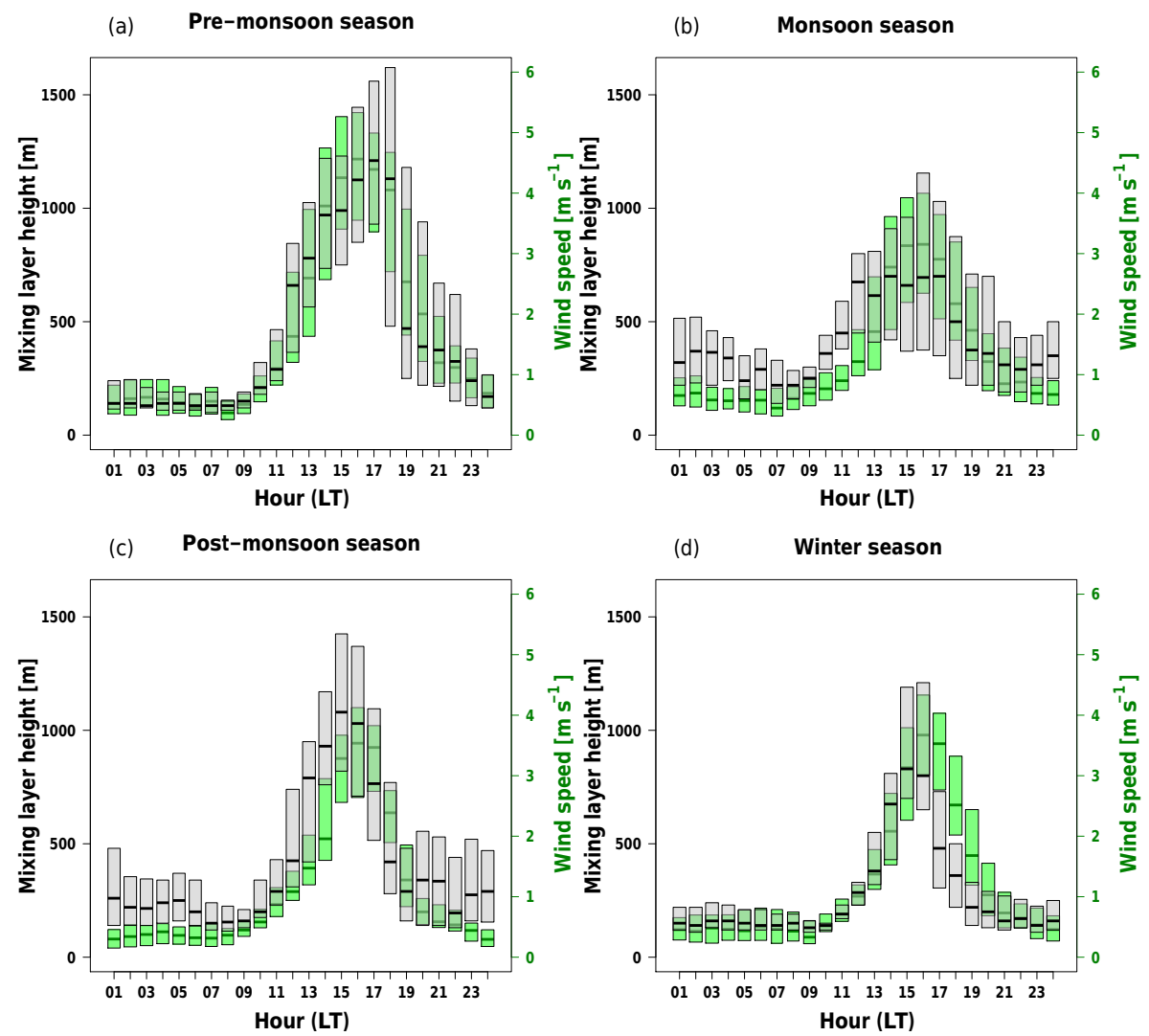

Figure 5. Mean diurnal cycle of the MLH (grey) and wind speed (green) as a boxplot (showing the median, the upper and lower quantile) for (a) the pre-monsoon (March-May 2013), (b) the monsoon (June-September 2013), (c) the post-monsoon (October-November 2013) and (d) the winter (December 2013-February 2014) season at the Bode station.

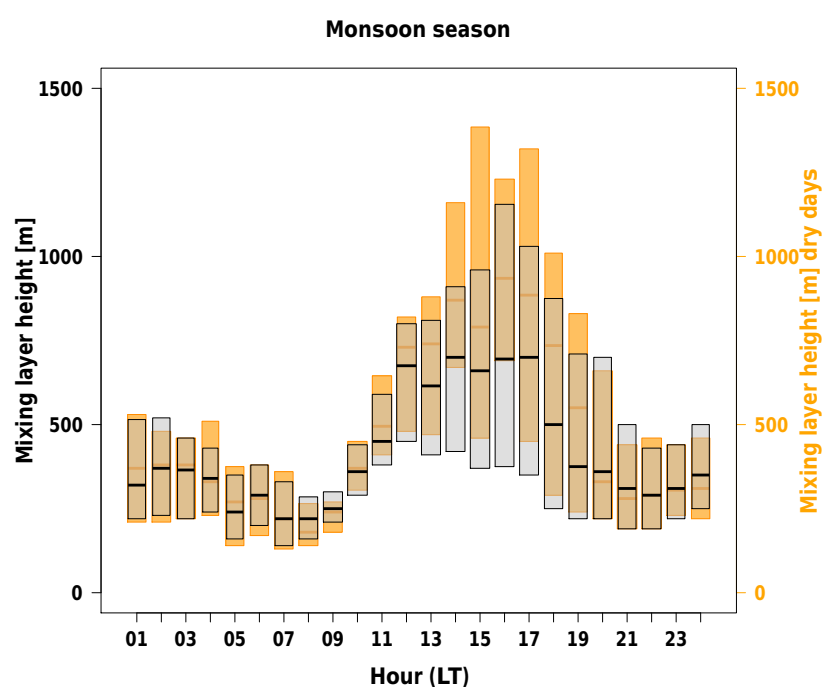

Figure 6. Diurnal cycle of the MLH with all days (grey) and only dry days (light orange) as a boxplot (showing the median, the upper and lower quantile) for the monsoon season (June-September 2013) at the Bode station. mountain valley is also important. Panday and Prinn (2009) and Panday et al. (2009) studied the dynamics of the basin's nocturnal cold air pool, its dissipation in the morning, and the growth and decay of the ML over the Kathmandu Valley during daytime in the dry season. These observations and additional model studies suggested that the cold pool dissipation was dominated by upslope flows along the valley rim accompanied by subsidence over the basin centre. In addition, during fog free days there was erosion of the inversion from below by the growth of thermals forming over a warming surface. They also found that the Kathmandu Valley's mixed layer height peaks around noon, and then decreases again over the course of the afternoon, which is consistent with the findings of this study.

\subsection{BC concentration and the MLH}

\subsubsection{Impact of the ML on BC concentration}

In this section the impact of the MLH on the concentration of $\mathrm{BC}$ is analysed and compared qualitatively to the impact of other important processes such as emissions, meteorological conditions and dry and wet deposition. The vertical structure of the ML is important for the concentrations of $\mathrm{BC}$ at 
the surface due to its impact on the volume into which pollutants are mixed, the strength of the vertical mixing and for the transport of pollutants into the residual layer in the evening and out of this layer into the ML in the morning. The correlation coefficients calculated for the time series of MLH and $\mathrm{BC}$ concentration with a time resolution of $1 \mathrm{~h}$ depend strongly on the season. While the Pearson coefficient for the pre-monsoon season is -0.54 , it is only -0.19 for the monsoon season $(-0.40$ for the post-monsoon and -0.46 for the winter season). This shows that a part of the variation in time of the BC concentration can be explained by atmospheric dynamics and that its magnitude depends on the season. Other processes important to explain the variability of the level of $\mathrm{BC}$ are temporal variation of emissions as well as large-scale transport and deposition. Important local emission sources of $\mathrm{BC}$ in the Kathmandu Valley are brick kilns which emit relatively constantly throughout day and night during the time period of December to April and are located in different parts of the valley (Fig. 1). Other important BC emission sources with a much more pronounced diurnal cycle are cooking, traffic (see location of main streets in Fig. 1) and refuse burning.

The ventilation coefficient, calculated as the product of the MLH and the $10 \mathrm{~m}$ wind speed, provides information on the intensity of the transport and mixing of pollutants within the ML (Tang et al., 2015). For this study wind speed measurements are only available at $15 \mathrm{~m}$ above the surface; thus, the calculated ventilation coefficients are expected to be slightly higher than when using the $10 \mathrm{~m}$ wind speed. The values of the ventilation coefficient at the Bode site are highest in the pre-monsoon and post-monsoon season (Fig. 7) with a maximum median of up to $5200 \mathrm{~m}^{2} \mathrm{~s}^{-1}$. In the monsoon and winter season the median values does not exceed 2000 and $3000 \mathrm{~m}^{2} \mathrm{~s}^{-1}$, respectively. During night time the ventilation coefficients show a small variation with a median minimum of only 43 and $105 \mathrm{~m}^{2} \mathrm{~s}^{-1}$ depending on the season. This suggests that during the night, stable stratification and the consequential low mixing and the transport of air pollutants are very small potentially resulting in a strong accumulation within the ML. Median daytime values of the ventilation coefficient above $1000 \mathrm{~m}^{2} \mathrm{~s}^{-1}$ occur only between four (monsoon and winter) and eight (pre-)monsoon hours per day. Pollutants are thus mixed and transported only during relatively short periods. These low ventilation coefficients during night time indicate that local emission sources play an important role in the high air pollution levels observed in the valley.

For the analysis of the impact of the MLH on the BC concentration in Fig. 8 the measured MLHs were grouped into classes in such a way that the impact of other meteorological drivers is minimised (Wagner, 2014). The optimum size of the classes (C) is different for each season and is approximated using the approach of Sturges (1926) relating the range of values ( $R=$ MLHmax - MLHmin) and the total number of values $(n)$ as follows:
$C=\frac{R}{(1+3.322 \times \lg (n))}$.

For every MLH class the median of the corresponding black carbon measurements is shown by the height of the bars in Fig. 8. The widths of the bars indicate the number of BC measurements available per class. The figure shows that there is typically a clear anticorrelation of the BC concentration and the MLH in all seasons except for the monsoon season. The strength of the decrease of BC concentration with increasing MLH, however, differs substantially between the seasons. In general, BC concentrations are high when the MLH is low and vice versa. This is mostly due to the larger volume into which pollutants can be vertically mixed and the associated stronger turbulence (and thus mixing) when the ML is high. The described relation between the two parameters is also illustrated in the diurnal cycle of the BC concentration and the MLH shown in Fig. 9. In all seasons the $\mathrm{BC}$ concentration shows a minimum during the day when the MLH is at its maximum.

In the pre-monsoon season the highest $\mathrm{BC}$ concentrations (around $30 \mu \mathrm{g} \mathrm{m}^{-3}$ ) are measured when the ML is below about $200 \mathrm{~m}$ (Fig. 8a) as it is the case during the night (Fig. 9a). MLHs above $200 \mathrm{~m}$ are mostly measured during daytime when the median concentrations are low (around $5 \mu \mathrm{g} \mathrm{m}^{-3}$ ). After about 18:00 the decrease in MLH goes along with an increase in the BC concentration which is caused to a large extent by the decreasing height and thus decreasing volume of the mixing layer (Fig. 8a). The maximum BC concentrations coincide with the minimum of the MLH in the morning hours. The relationship between the BC concentration and the MLH is similar in winter and the premonsoon season (Fig. 9a and d).

In the monsoon season the anticorrelation between the $\mathrm{BC}$ concentration and the MLH is not as strong as in the other seasons (Fig. 8b). The BC concentrations are high for MLHs below $200 \mathrm{~m}$ but the decrease in BC concentration with the increase of the MLH is less pronounced and for very large MLHs the BC concentrations even increase. This suggests that other processes than the temporal evolution of the MLH such as the temporal variation of local emissions strengths are also of importance here. In contrast to the pre-monsoon and winter season, the diurnal cycle of the BC concentration in the monsoon season shows a second maximum in the evening hours (around 20:00) (Fig. 9b). The increase in the concentration in the afternoon is stronger than in the premonsoon season. But despite a further decrease of the MLH the $\mathrm{BC}$ concentration decreases again in the evening and remains on a nearly constant level during the night until it increases again in the early morning towards the daily maximum in the morning (at around 08:00). These main characteristics of the $\mathrm{BC}$ diurnal cycle remain the same when only considering dry days (Fig. 10). This suggests that more frequent precipitation events and thus wet deposition is not 
(a)

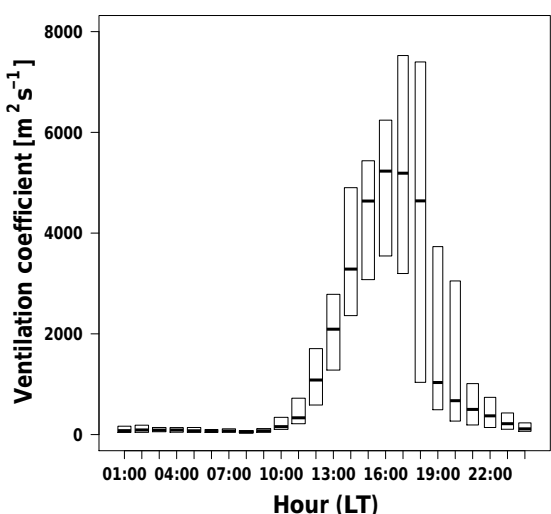

(c) Post-monsoon season

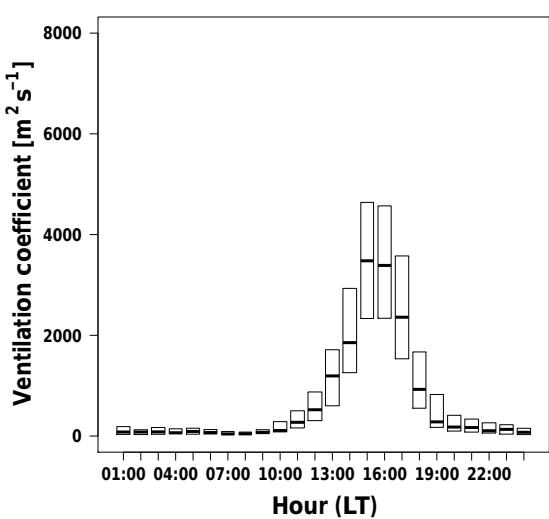

(b)

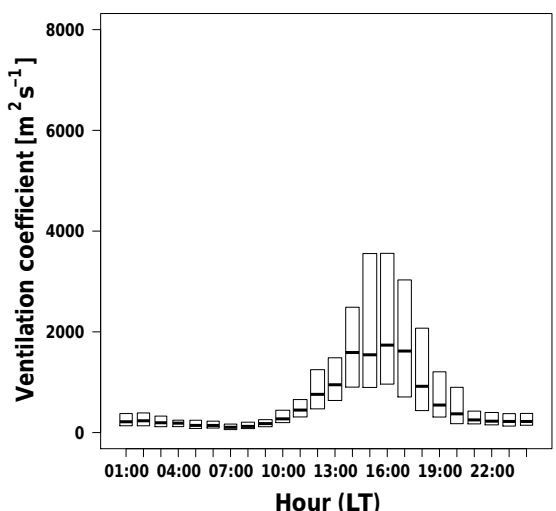

(d)

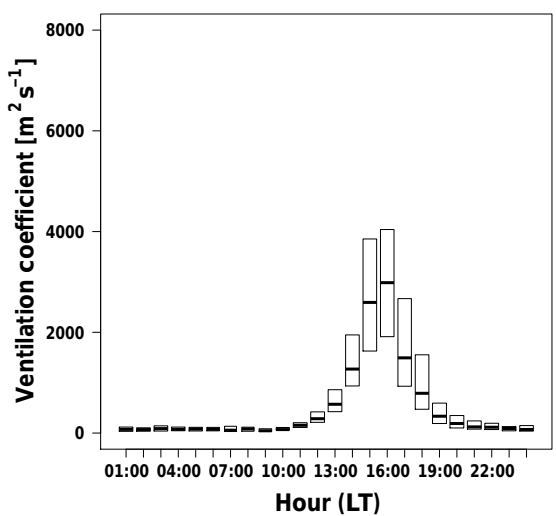

Figure 7. Diurnal cycle of the ventilation coefficient as a boxplot (showing the median, the upper and lower quantile) for the (a) premonsoon (March-May 2013), (b) the monsoon (June-September 2013), (c) the post-monsoon (October-November 2013) and (d) the winter (December 2013-February 2014) season at the Bode site.

the main reason for this decrease in $\mathrm{BC}$ concentrations after 20:00. The diurnal cycle of $\mathrm{BC}$ in the post-monsoon season shows a similar shape as in the monsoon season although the second peak in the afternoon is less pronounced and the concentrations are somewhat higher.

In Putero et al. (2015) BC measurements at an urban site located in the west of the Kathmandu Valley are described and discussed. In all seasons a diurnal cycle of BC typical for an urban site with two daily maxima, one prominent peak in the morning and a second peak in the evening as well as minima at night and in the afternoon was found. Panday and Prinn (2009) observed such a diurnal cycle also for carbon monoxide $(\mathrm{CO})$ and particulate matter $\left(\mathrm{PM}_{10}\right)$. Their analysis based on observations shows that this double peak results from an interplay between the timing of the emissions and ventilation. And also Shrestha et al. (2016) describe daily twin peaks of aerosol concentration in the valley attributed to calm conditions followed by transitional growth and break down of the valley boundary layer below. Putero et al. (2015) argue that the first daily $\mathrm{BC}$ peak can be explained by increased emissions from, for example, traffic and cooking ac- tivities under stable atmospheric conditions and a low MLH. Over the course of the day, the valley is ventilated by westerly winds entering through the western passes, the dilution within the higher PBL and decrease of emissions can explain the daily minimum in BC (Putero et al., 2015). When the PBL height starts to decrease due to the decrease in solar radiation and surface heating along with the higher emissions of evening traffic and cooking activities, a secondary peak in BC is observed in Putero et al. (2015). The authors argue that the following decrease in $\mathrm{BC}$ concentrations is caused by the decrease in traffic and domestic emissions and a less efficient vertical mixing within a more stable ML. But a less efficient vertical mixing would rather lead to increased or constant level of pollutants. In general the above-mentioned findings and explanations are most likely also valid for the diurnal BC concentrations at the Bode station in the monsoon and postmonsoon season as it shows the same main characteristics (westerly wind, highest wind speeds during daytime, highest MLH).

In contrast, the diurnal cycle of the $\mathrm{BC}$ concentration observed at the Bode station during the pre-monsoon and winter 
(a)

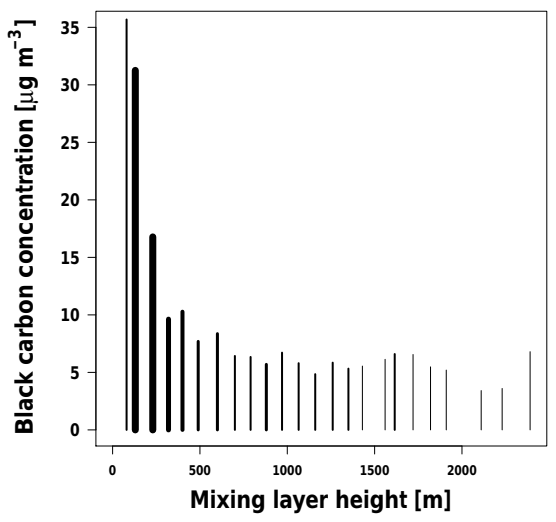

(c)

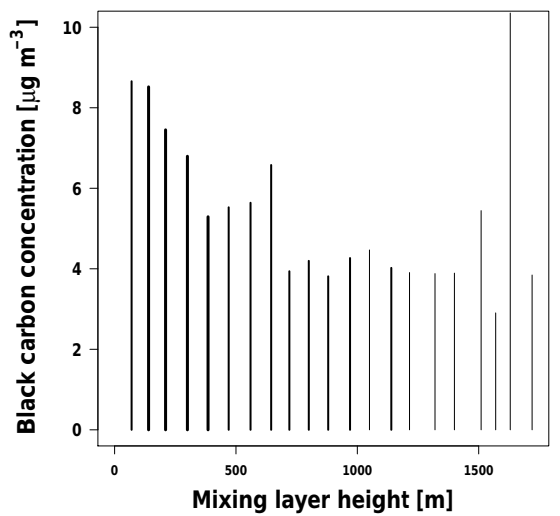

(b)

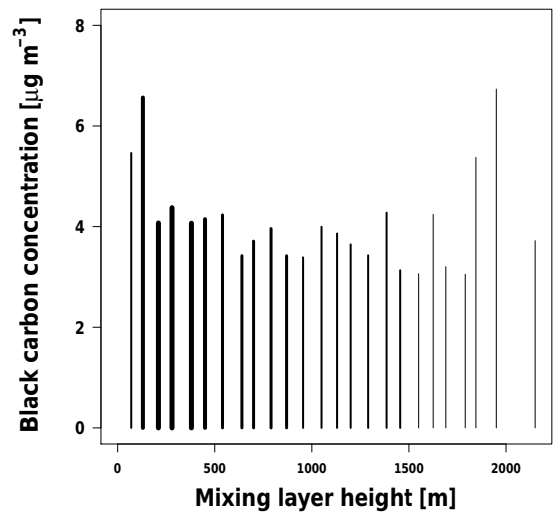

(d) Winter season

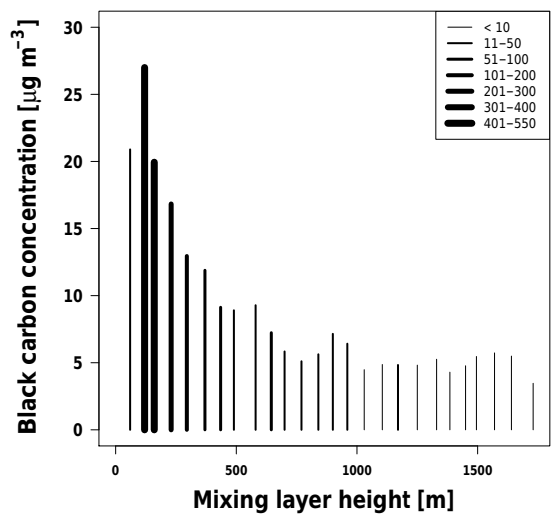

Figure 8. Dependency of the BC concentration on the MLH for (a) the pre-monsoon (March-May 2013), (b) the monsoon (June-September 2013), (c) the post-monsoon (October-November 2013) and (d) the winter (December 2013-February 2014) season. The concentration refers to a (a) $92 \mathrm{~m}$, (b) $82 \mathrm{~m}$, (c) $85 \mathrm{~m}$, and (d) $74 \mathrm{~m}$ interval of the MLH (see explanation in Sect. 3.3). The widths of the bars indicate the number of data points, as given in the legend in (d).

season shows one maximum in the morning hours. For the pre-monsoon season also the anticorrelation of the diurnal cycle of the BC concentration and the MLH as well as of the wind speed in the morning and daytime in the pre-monsoon season suggests that a large part of the BC diurnal cycle is driven by atmospheric dynamics. The missing second peak in the evening indicates that other processes than described above are dominating here. Because differences between the $\mathrm{BC}$ diurnal cycles in the different seasons were not found in Putero et al. (2015) the exact location of the station seems to be an important factor. Putero et al. (2015) argue that the diurnal cycle of the $\mathrm{BC}$ concentration indicates that local pollution sources, mostly related to road traffic or domestic emissions, represent the main contribution to air pollution in the valley. The Bode site is not located directly in the urban core area but more towards the rather suburban east. Pollution roses (not shown) show that between about December and April most of the highest BC concentrations coincide with wind from the east and east-southeast. This is where a number of brick kilns are located which operate mainly during this time of the year. The brick kilns emit continuously throughout the day, whereas in the other months sources with more pronounced diurnal cycles, such as traffic and cooking activities, are dominating the total $\mathrm{BC}$ emissions. Thus, in addition to the circulation in the valley, the location and the main emission sources as well as the time profiles of these sources have a great impact on the BC concentrations as well as their diurnal cycle in each season.

Highest $\mathrm{BC}$ concentrations are measured during the premonsoon and winter season (Fig. 9a and d), which was also found by Putero et al. (2015). Several processes can lead to these high concentrations. In the winter season the low MLH and wind speed favour the accumulation of pollutants due to the limited transport and vertical mixing. But in the premonsoon season, high BC concentrations are observed, despite the comparable high ventilation coefficient (Fig. 7a). Additional emission sources such as domestic heating and brick kilns as well as the lack of precipitation are expected to be the main factors leading to the high $\mathrm{BC}$ concentrations during these seasons. In the monsoon season wet deposition of $\mathrm{BC}$ by precipitation leads to a lower level of BC concentration in the atmosphere. 
(a)

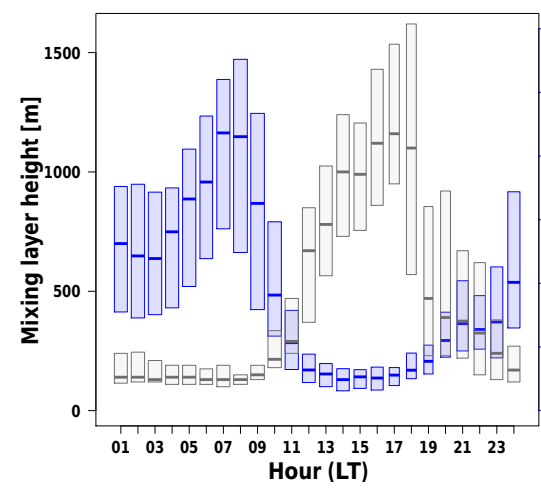

(c) Post-monsoon season

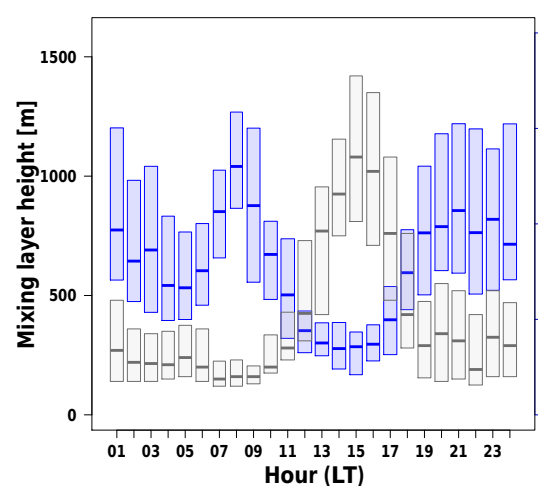

(b)

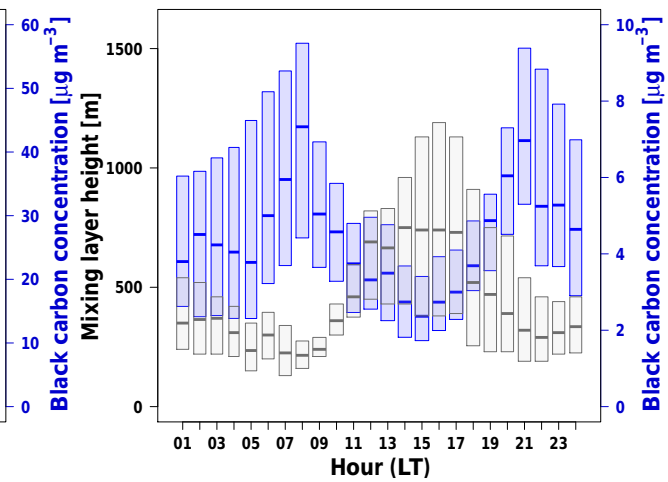

(d)

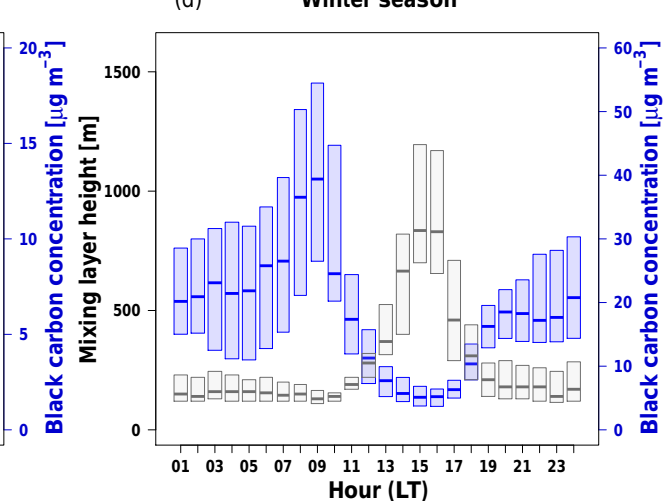

Figure 9. Diurnal cycle of the MLH (grey) and the BC concentration (blue) as a boxplot (showing the median, the upper and lower quantile) for (a) the pre-monsoon (March-May 2013), (b) the monsoon (June-September 2013), (c) the post-monsoon (October-November 2013) and (d) the winter (December 2013-February 2014) season at the Bode station.

\subsubsection{Estimation of $\mathrm{BC}$ emission fluxes}

The annual mean emission estimates from EDGAR HTAP inventory v2.2 (Janssens-Maenhout et al., 2000) for the Kathmandu region range between $28 \mathrm{ng} \mathrm{m}^{-2} \mathrm{~s}^{-1}$ in winter and $19 \mathrm{ng} \mathrm{m}^{-2} \mathrm{~s}^{-1}$ in rest of the year (annual mean $=$ $21 \mathrm{ng} \mathrm{m}^{-2} \mathrm{~s}^{-1}$ ). EDGAR HTAP has a resolution of $0.1^{\circ}$ and is based in this region on data from the REAS emission database (Kurokawa et al., 2013) which has a resolution of $0.25^{\circ}$. First test simulations (not shown) with the WRFChem model (Grell et al., 2005; Fast et al., 2006) using this emission inventory underestimate the observed BC at the Bode station by a factor of about 8 in February 2013. (More information on the model set-up used for these simulations is presented in the Supplement.) The measured monthly mean $\mathrm{BC}$ concentrations at the Bode station are in the range of 3.4 and $25.9 \mu \mathrm{g} \mathrm{m}^{-3}$ between March 2013 and February 2014. BC concentrations in a similar range were measured for example in Delhi and Mumbai in India. In Tiwari et al. (2015) monthly mean concentrations from 6.4 to $20.3 \mu \mathrm{g} \mathrm{m}^{-3}$ averaged over five stations in Delhi were measured between September 2010 and January 2011. In Mumbai measured $\mathrm{BC}$ levels during winter season ranged from
3.2 to $9.4 \mu \mathrm{g} \mathrm{m}^{-3}$, compared to 1.0 to $6.9 \mu \mathrm{g} \mathrm{m}^{-3}$ in summer and 1.0 to $5.8 \mathrm{\mu g} \mathrm{m}^{-3}$ in the monsoon season (Sandeep et al., 2013). For these two cities the EDGAR HTAP emission database gives annual mean emission fluxes for BC of $169 \mathrm{ng} \mathrm{m}^{-2} \mathrm{~s}^{-1}$ for Delhi and $600 \mathrm{ng} \mathrm{m}^{-2} \mathrm{~s}^{-1}$ for Mumbai. The underestimation of the measured $\mathrm{BC}$ concentration at the Bode station with the model, their similarity to measurements in Delhi and Mumbai, and the higher emission flux in the EDGAR HTAP database for Delhi and Mumbai suggest that the $\mathrm{BC}$ emission estimates might be underestimated for the Kathmandu region. This also appears to apply to other current emission inventories such as INTEX-B (Zhang et al., 2009), with emissions value of $21.1 \mathrm{ng} \mathrm{m}^{-2} \mathrm{~s}^{-1}$ for the Kathmandu Valley.

In this part of the study an estimate of the $\mathrm{BC}$ emission flux for the morning hours is presented using the observed MLH and BC concentrations at the Bode site. The method proposed here to obtain an estimate of the $\mathrm{BC}$ emission flux is mainly based on three assumptions:

- BC aerosols are horizontally and vertically well mixed within the ML, 
Table 2. Terms for the estimation of the BC emission flux as used in Eq. (3) and estimated BC emission flux for four seasons during the period March 2013 to February 2014.

\begin{tabular}{lllrrr}
\hline Season 2013/2014 & $\begin{array}{l}t_{x} \text { and } t_{y} \\
\text { (local time) }\end{array}$ & MLH $\left(t_{x}\right) / \operatorname{MLH}\left(t_{y}\right)$ & $\begin{array}{r}\left.\text { average(MLH }\left(t_{x}\right), \operatorname{MLH}\left(t_{y}\right)\right) \\
(\mathrm{m})\end{array}$ & $\begin{array}{r}\Delta \mathrm{BC} \\
\left(\mu \mathrm{g} \mathrm{m}^{-3}\right)\end{array}$ & $\begin{array}{r}\mathrm{BC} \text { emission flux } F_{\mathrm{BC}} \\
\left(\mathrm{ng} \mathrm{m}^{-2} \mathrm{~s}^{-1}\right)\end{array}$ \\
\hline Mar-May 2013 & $04: 00,09: 00$ & 1.21 & 164.30 & 17.05 & 188 \\
Jun-Sep 2013 & $05: 00,09: 00$ & 1.36 & 288.00 & 2.34 & 64 \\
Oct-Nov 2013 & $05: 00,09: 00$ & 1.41 & 244.22 & 4.98 & 118 \\
Dec 2013-Feb 2014 & $05: 00,10: 00$ & 1.33 & 173.48 & 19.46 & 248 \\
\hline
\end{tabular}

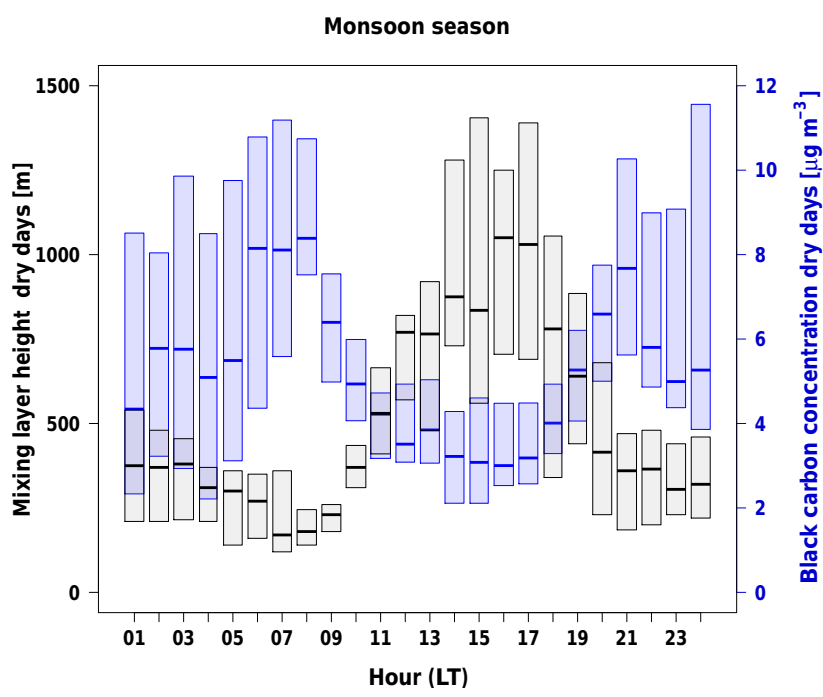

Figure 10. Diurnal cycle of the MLH (grey) and the BC concentration (blue) for only dry days as a boxplot (showing the median, the upper and lower quantile) for the monsoon season (June-September 2013) at the Bode station.

- the variation of the MLH is only small at night as frequently observed in the measurements (Fig. 3),

- the horizontal transport of air pollutants into and out of the valley and the vertical mixing of pollutants between the ML and the free atmosphere is assumed to be negligible at night.

This means that the $\mathrm{BC}$ concentration measured at the Bode station is assumed to represent the BC load in the column around the station and throughout the valley with the top corresponding to the height of the ML, and thus the product of the measured BC and the MLH represents the BC mass per unit area within this column. The third assumption is based on the observation that the wind speed is typically very low $\left(<1 \mathrm{~m} \mathrm{~s}^{-1}\right)$ during the night (Fig. 5), and thus the horizontal transport of air pollutants into and out of the valley is assumed to be negligible. The assumption of negligible horizontal transport at night is consistent with the observed low nocturnal wind speeds, and with the studies by Panday and Prinn (2009) and Panday et al. (2009), who found that the timing of the ventilation of air pollutants from the valley is largely determined by the strong westerly wind typically blowing through the valley from late morning until dusk. The authors of these studies conclude that the bulk of the ventilation of air pollutants usually takes place in the afternoon. Consequently, the horizontal advection of air pollutants into and out of the valley is typically small at night. And the mixing of pollutants between the ML and the free atmosphere (entrainment) occurs mostly when the MLH increases or decreases significantly, which is not the case during the hours used for this calculation (Table 2 and Fig. 9). The assumption that vertical mixing of pollutants between the ML and the free troposphere is small at night is consistent with the findings by Regmi et al. (2003), who concluded that during night hours, the typically prevailing meteorology leads to a strong surface inversion and formation of a deep cold-air lake in the valley under weak wind, which suppresses vertical mixing. This suggests that the main process driving the increase of the $\mathrm{BC}$ concentration during the night is not the variation in the mixing layer height (Fig. 9), nor mixing of even more polluted air from above or from outside the valley, but rather, as assumed here, the emissions. Assuming that the air in the free troposphere and outside the valley is actually less polluted than in the highly populated valley, then any mixing would require a higher emissions rate to compensate the reduction in pollution levels due to mixing, and thus neglecting transport and mixing implies that we will tend to underestimate the actual emissions in the morning hours. Dry deposition is expected to have a negligible effect on the observed mass densities during the course of a single night, given the residence time for fine $\mathrm{BC}$ particles of approximately 6 days (Cape et al., 2012), which implies a loss of only approximately $1 / 144$ of the BC concentration per hour (i.e. in the range of a few $\mathrm{ng} \mathrm{m}^{-2} \mathrm{~s}^{-1}$ for the nighttime measurements period). Thus not accounting for dry deposition also implies a small underestimate of the emissions. Wet deposition is a very efficient removal mechanism for BC. Since we do not account for wet deposition in the calculation, this will also imply that the estimated emission fluxes are an underestimate, especially for months with high precipitation rates. With these three factors together, we can consider our emissions estimate to likely be a lower bound to the actual emissions rate in the morning hours. 
The difference between the maximum and minimum $\mathrm{BC}$ concentration $\left(\triangle \mathrm{BC}=\mathrm{BC}\left(t_{y}\right)-\mathrm{BC}\left(t_{x}\right)\right)$ in the night $\left(t_{x}\right)$ and morning hours $\left(t_{y}\right)$, represents the increase in the $\mathrm{BC}$ concentration during this time period. $t_{x}$ refers to the hour with the $\mathrm{BC}$ concentration minimum in the night and $t_{y}$ to the hour with the $\mathrm{BC}$ concentration maximum in the morning hours. If the MLH were constant, and there were no vertical or lateral mixing into the valley, then the product of $\triangle \mathrm{BC}$ and the MLH divided by the time difference $\Delta t\left(\Delta t=t_{y}-t_{x}\right)$ would yield the average emission flux $F_{\mathrm{BC}}\left(t_{x}, t_{y}\right)$ in this time period, i.e. the additional $\mathrm{BC}$ mass per unit area which is necessary to balance the observed increase in BC concentration between the night $\left(t_{x}\right)$ and morning hour $\left(t_{y}\right)$. However, the MLH is not constant. Since the relative variation during the chosen period is small, a first-order estimate can be obtained by using the average $\operatorname{MLH}\left(\operatorname{ave}\left(\operatorname{MLH}\left(t_{x}\right), \operatorname{MLH}\left(t_{y}\right)\right)\right.$ between $t_{x}$ and $t_{y}$ in the calculation. To additionally account for the small change (in general a decrease) in the MLH between the night and the morning hours, a "mixing layer collapse factor" needs to be introduced $\left(\operatorname{MLH}\left(t_{y}\right) / \operatorname{MLH}\left(t_{x}\right)\right)$. This factor can be understood by considering that if there were no mixing with the atmosphere outside the valley during these hours, and deposition were negligible, then the $\mathrm{BC}$ mass would be preserved within the ML, and the concentration would increase accordingly as the mass is compressed into a smaller volume. These terms are summarised in Eq. (3), which is used to estimate the BC emission flux $F_{\mathrm{BC}}\left(t_{x}, t_{y}\right)$ for the morning hours per month at the station. The equation as written also accounts for the conversion from $\mu \mathrm{g}$ to $\mathrm{ng}$ (factor 1000) and from hours to seconds (factor 3600):

$$
\begin{aligned}
& F_{\mathrm{BC}}\left(t_{x}, t_{y}\right)=\frac{\Delta \mathrm{BC} \times 1000 \times \operatorname{ave}\left(\operatorname{MLH}\left(t_{x}\right), \operatorname{MLH}\left(t_{y}\right)\right)}{\Delta t \times 3600} \\
& \quad \times \frac{\operatorname{MLH}\left(t_{y}\right)}{\operatorname{MLH}\left(t_{x}\right)},
\end{aligned}
$$

with $F_{\mathrm{BC}}\left(t_{x}, t_{y}\right)$ the BC emission flux between time $t_{x}$ and $t_{y}$ in $\mathrm{ng} \mathrm{m}^{-2} \mathrm{~s}^{-1}, \triangle \mathrm{BC}$ the black carbon concentration difference between $t_{y}$ and $t_{x}$ in $\mu \mathrm{g} \mathrm{m}^{-3}$, ave $\left(\operatorname{MLH}\left(t_{x}\right), \operatorname{MLH}\left(t_{y}\right)\right)$ the average of the MLH between $t_{x}$ and $t_{y}$ in $\mathrm{m}, \Delta t=t_{y}-t_{x}$ in $\mathrm{h}$ and $\operatorname{MLH}\left(t_{y}\right) / \operatorname{MLH}\left(t_{x}\right)$ the "mixing layer collapse factor". The emission fluxes are calculated based on the mean diurnal cycles per month; $t_{x}$ and $t_{y}$ are chosen such that they represent the time with the minimum $\left(t_{x}\right)$ and maximum $\left(t_{y}\right)$ $\mathrm{BC}$ concentration in the night and morning. These points in time are quite different for the individual months with a range of 01:00 to 05:00 for $t_{x}$ and 08:00 to 09:00 for $t_{y}$. As noted above, this approach will tend to underestimate the actual emissions rate in the morning hours, if either non-negligible amounts of cleaner air are mixed in from outside the valley, or if the deposition loss were much larger than expected based on the literature. Results from this calculation including the results from the different terms in Eq. (3) are given in Tables 2 and 3 for the four seasons and in Fig. 11 for every month.
Table 3. Estimated BC emission fluxes for four seasons for dry days $F_{\text {BCdrydays }}$ and $F_{\text {BCmin }}$ as estimated in Eq. (4).

\begin{tabular}{lrr}
\hline Season 2013/2014 & $\begin{array}{r}\text { BC emission flux } \\
\text { dry days } \\
F_{\text {BCdrydays }} \\
\left(\mathrm{ng} \mathrm{m}^{-2} \mathrm{~s}^{-1}\right)\end{array}$ & $\begin{array}{r}\text { BC emission flux } \\
\text { estimation of } \\
F_{\mathrm{BCmin}}(\text { Eq. 4) } \\
\left(\mathrm{ng} \mathrm{m}^{-2} \mathrm{~s}^{-1}\right)\end{array}$ \\
\hline Mar-May 2013 & 217 & 39 \\
Jun-Sep 2013 & 88 & 11 \\
Oct-Nov 2013 & 123 & 20 \\
Dec 2013-Feb 2014 & 254 & 52 \\
\hline
\end{tabular}

The BC emission flux estimates for the morning hours obtained with this method (Fig. 11) show a clear seasonal cycle with higher values in the months December to April (196-298 $\left.\mathrm{ng} \mathrm{m}^{-2} \mathrm{~s}^{-1}\right)$ than in the other months (26$\left.170 \mathrm{ng} \mathrm{m}^{-2} \mathrm{~s}^{-1}\right)$. These BC emission fluxes are of a similar order of magnitude to the ones from the EDGAR HTAP emission database especially for a highly polluted Indian city like Delhi, as noted previously. The seasonal variation computed for the emission flux estimates fit well to known seasonal characteristics of the main emission sources. In particular, brick kilns are known to be major emitters of BC in the Kathmandu Valley (Chen et al., 2016), and are only active from late December to April. The brick kilns typically emit continuously throughout day and night, whereas in the other months sources with more pronounced diurnal cycles, such as traffic and cooking activities, generally dominate the total emissions. In order to consider the daily variability of the estimated emission flux for each month, values based on the 25 th and 75 th percentile of the diurnal cycles are also shown (Fig. 11).

The emission estimates computed here are subject to further uncertainties in addition to those noted above. One of these uncertainties is the assumption that the measurements at the Bode site are representative for the whole atmospheric column and the surrounding region, which is difficult to verify without more extensive simultaneous measurements throughout the valley. Furthermore, while the diurnal cycles of BC during January to May and November to December have a relatively clear minimum and maximum in night and morning hours, the diurnal cycles of the months June to October show a much higher variability. This makes it more difficult to choose the hour with the minimum and maximum BC concentration for the estimation of the flux, and thus adds another uncertainty. On the other hand, the differences between the 25th and 75th percentile for these periods are relatively small, indicating a greater consistency in the diurnal cycle from day to day in June to October than in the other months.

As a final uncertainty to consider, the possible impact of wet deposition is not included, which would also cause to tend to generally underestimate the emissions rate if $\mathrm{BC}$ is 


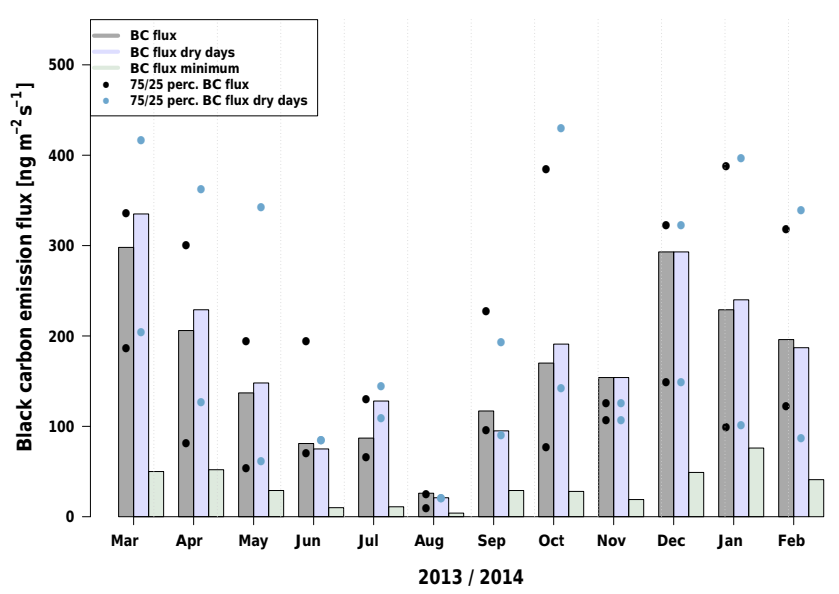

Figure 11. Seasonal cycle of the estimated BC emission flux based on the mean diurnal cycle per month using the data of all days $\left(F_{\mathrm{BC}}\right)$ (grey) and only dry days ( $\left.F_{\mathrm{BCdrydays}}\right)$ (blue) and with only using the estimated flux in the morning hours and for other hours zero flux is used $\left(F_{\mathrm{BCmin}}\right)$ (green).

being lost during the day due to wet deposition (similar to the effect of dry deposition noted above). While we cannot directly calculate the effect of wet deposition, we can filter out all days with a sum of precipitation of more than $0.5 \mathrm{~mm}$ per day, thus only taking dry days into account in the flux calculation (Table 3). As could be expected, using only dry days generally leads to higher calculated emission fluxes in most of the months compared to considering all days. The differences of the estimated emission flux between all days and dry days range between -9 and $37 \mathrm{ng} \mathrm{m}^{-2} \mathrm{~s}^{-1}$. In June, August, September and February the differences are negative, which is likely to be due to the lack of sufficient data to get good statistics for the dry days (e.g. $24 \%$ of the time in the monsoon season for $\mathrm{BC}$, respectively); this may also be influenced by other confounding factors, such as differences in ML characteristics, vertical mixing and horizontal wind speeds on wet versus dry days. Furthermore, precipitation in other parts of the valley, which will generally also have an impact on the measured $\mathrm{BC}$ concentration at the Bode station, is not taken into account by this approach.

Finally, the estimated BC emission fluxes are only valid for the morning hours for which the calculation in Eq. (3) is applied. The implicit assumption in Fig. 11 is that the emission rate during this period is representative of the rest of the $24 \mathrm{~h}$ period as well. This assumption may not be valid; for example, the morning period generally includes the emissions peak from the morning rush hour traffic. While we cannot compute exactly what the $24 \mathrm{~h}$ emissions are based on this technique, without currently unavailable information about the diurnal profiles of all main $\mathrm{BC}$ sources, it is possible to use the calculation to determine an absolute lower bound on the local emissions, by assuming that the emission rate during all hours of the day which are not covered in Eq. (3) is zero:

$F_{\mathrm{BCmin}}=F_{\mathrm{BC}} \times \frac{\Delta t}{24}$.

The results of this calculation (Table 3 and Fig. 11) show for all months except the monsoon season (June until August), even this absolute minimum for the $24 \mathrm{~h}$ estimated emission fluxes are still higher than the values in the EDGAR HTAP database $\left(28 \mathrm{ng} \mathrm{m}^{-2} \mathrm{~s}^{-1}\right.$ in winter and $19 \mathrm{ng} \mathrm{m}^{-2} \mathrm{~s}^{-1}$ during rest of the year, as noted above). Thus, even if our analysis may be biased towards overestimating the $24 \mathrm{~h}$ emissions by including the morning rush hour and other activities (e.g. cooking), they nevertheless provide strong evidence that the emission fluxes in the EDGAR HTAP emission inventory and the other inventories noted above are likely too low for this region.

\section{Summary and outlook}

The data of MLH derived from ceilometer measurements analysed in this study represent a unique dataset and important information for the analysis of the meteorological and air quality conditions in the Kathmandu region. The time series and especially the diurnal cycles of the MLH show different characteristics in the four seasons. In all seasons the diurnal cycle shows low mixing heights during the night and increasing and maximum values during the day but with seasonal differences in the absolute values of the MLH and the duration of the daytime maximum. Different meteorological parameters such as solar radiation, wind speed and precipitation have been shown to be of key importance to explain these differences between the seasons. During the monsoon season the observed diurnal cycle of the MLH deviates from that obtained for other seasons by showing the lowest amplitude and the lowest MLH during the day and the highest in the night and morning hours of all seasons. These characteristics can mainly be explained with frequently present clouds and the associated reduction in incoming solar radiation and outgoing longwave radiation.

In general there is a clear anticorrelation of the BC concentration and the MLH although this relation is less pronounced in the monsoon season. The daily evolution of the BC diurnal cycle differs between the seasons, partly due to the different meteorological conditions including the MLH. Another important reason is the different main emission sources and their diurnal emission profiles relevant in the individual seasons. From January to April for example brick kilns, which emit continuously throughout the whole day, are major emitters of $\mathrm{BC}$, whereas in the other months sources with more pronounced diurnal cycles are dominating the total emissions. 
Using the MLH data and the BC measurements an estimation of the $\mathrm{BC}$ emission flux for the night and morning hours was calculated. Even though these estimates are subject to a range of uncertainties, they give a first top-down estimate of the order of magnitude of BC emissions in the Kathmandu Valley based solely on measurements. The estimated values show a clear seasonal cycle with high values for the months December to April. Compared to the emission flux values provided by different emission databases for this region, the values estimated here are considerably higher. Even accounting for a lower bound for the estimated minimum BC emission flux values by assuming no emissions outside the nighttime and morning hours used for the calculation still yields values which are higher than in the emissions databases for all seasons except the monsoon season.

Data availability. Data used in this study can be obtained by sending an email to the corresponding authors. They will also be made publicly available through the IASS website.

\section{The Supplement related to this article is available online at https://doi.org/10.5194/acp-17-8157-2017-supplement.}

Competing interests. The authors declare that they have no conflict of interest.

Acknowledgements. We would like to acknowledge Shyam Newar, Bhogendra Kathayat and Ravi Ram Pokhrel for their support in operating the ceilometer and Aethalometer at the Bode site, and Arnico Panday and his colleagues from ICIMOD for logistical support to deployment of instruments and running the Bode site. Financial support for this study was provided by the German Research Foundation (DFG), the Federal Ministry of Education and Research of Germany (BMBF) and the Ministry for Science, Research and Culture of the State of Brandenburg (MWFK). We would also like to thank Ashish Singh for processing the measurement data.

Edited by: Elizabeth Stone

Reviewed by: two anonymous referees

\section{References}

Aryal, R. K., Lee, B. K., Karki, R., Gurung, A., Baral, B., and Byeon, S. H.: Dynamics of PM2.5 concentrations in Kathmandu Valley, Nepal, Journal of Hazardous Materials, 168, 732-738, https://doi.org/10.1016/j.jhazmat.2009.02.086, 2009.

Bond, T. C., Doherty, S. J., Fahey, D. W., Forster, P. M., Berntsen, T., Deangelo, B. J., Flanner, M. G., Ghan, S., Kärcher, B., Koch, D., Kinne, S., Kondo, Y., Quinn, P. K., Sarofim, M. C.,
Schultz, M. G., Schulz, M., Venkataraman, C., Zhang, H., Zhang, S., Bellouin, N., Guttikunda, S. K., Hopke, P. K., Jacobson, M. Z., Kaiser, J. W., Klimont, Z., Lohmann, U., Schwarz, J. P., Shindell, D., Storelvmo, T., Warren, S. G., and Zender, C. S.: Bounding the role of black carbon in the climate system: A scientific assessment, J. Geophys. Res.-Atmos., 118, 5380-5552, https://doi.org/10.1002/jgrd.50171, 2013.

Cape, J. N., Coyle, M., and Dumitrean, P.: The atmospheric lifetime of black carbon, Atmos. Environ., 59, 256-263, https://doi.org/10.1016/j.atmosenv.2012.05.030, 2012.

Chen, P., Li, C., Kang, S., Yan, F., Zhang, Q., Ji, Z., Tripathee, L., Rupakheti, D., Rupakheti, M., Qu, B., and Sillanpää, M.: Source apportionment of particle-bound polycyclic aromatic hydrocarbons in Lumbini, Nepal by using the positive matrix factorization receptor model, Atmos. Res., 182, 46-53, https://doi.org/10.1016/j.atmosres.2016.07.011, 2016.

Drinovec, L., Mocnik, G., Zotter, P., Prévôt, A. S. H., Ruckstuhl, C., Coz, E., Rupakheti, M., Sciare, J., Müller, T., Wiedensohler, A., and Hansen, A. D. A.: The "dual-spot" Aethalometer: an improved measurement of aerosol black carbon with realtime loading compensation, Atmos. Meas. Tech., 8, 1965-1979, https://doi.org/10.5194/amt-8-1965-2015, 2015.

Emeis, S., Schäfer, K., and Münkel, C.: Surface-based remote sensing of the mixing-layer height - A review, Meteorol. Z., 17, 621630, https://doi.org/10.1127/0941-2948/2008/0312, 2008.

Emeis, S., Schäfer, K., Münkel, C., Friedl, R., and Suppan, P.: Evaluation of the Interpretation of Ceilometer Data with RASS and Radiosonde Data, Bound.-Lay. Meteorol., 143, 25-35, 2012.

Eresmaa, N., Karppinen, A., Joffre, S. M., Räsänen, J., and Talvitie, H.: Mixing height determination by ceilometer, Atmos. Chem. Phys., 6, 1485-1493, https://doi.org/10.5194/acp-6-1485-2006, 2006.

Fast, J. D., Gustafson Jr, W. I., Easter, R. C., Zaveri, R. A., Barnard, J. C., Chapman, E. G., Grell, G. A., and Peckham, S. E.: Evolution of ozone, particulates, and aerosol direct radiative forcing in the vicinity of Houston using a fully coupled meteorology-chemistry-aerosol model, J. Geophys. Res.-Atmos., 111, D21305, https://doi.org/10.1029/2005JD006721, 2006.

Grell, G. A., Peckham, S. E., Schmitz, R., McKeen, S. A., Frost, G., Skamarock, W. C., and Eder, B.: Fully coupled "online" chemistry within the WRF model, Atmos. Environ., 39, 6957-6975, https://doi.org/10.1016/j.atmosenv.2005.04.027, 2005

Haeffelin, M., Angelini, F., Morille, Y., Martucci, G., Fry, S., Gobbi, G. P., Lolli, S., O’Dowd, C. D., Sauvage, L., Xueref-Rèmy, I., Wastine, B., and Feist, D. G.: Evaluation of Mixing-Height Retrievals from Automatic Profiling Lidars and Ceilometers in View of Future Integrated Networks in Europe, Bound.-Lay. Meteorol., 143, 49-75, https://doi.org/10.1007/s10546-011-9643-z, 2012.

Hansen, A. D. A., Rosen, H., and Novakov, T.: Real-time measurement of the aerosol absoprtion-coefficient of aerosol particles, Appl. Optics, 21, 3060-3062, 1982.

Hansen, A. D. A., Rosen, H., and Novakov, T.: The aethalometeran instrument for the real-time measurement of optical absorption by aerosol particles, Sci. Total Environ., 36, 191-196, 1984.

Helmis, C. G., Sgouros, G., Tombrou, M., Schäfer, K., Münkel, C., Bossioli, E., and Dandou, A.: A Comparative Study and Evaluation of Mixing-Height Estimation Based on Sodar-RASS, Ceilometer Data and Numerical Model Simulations, Bound.- 
Lay. Meteorol., 145, 507-526, https://doi.org/10.1007/s10546012-9743-4, 2012.

Janssens-Maenhout, G., Dentener, F., van Aardenne, J., Monni, S., Pagliari, V., Orlandini, L., Klimont, Z., Kurokawa, J., Akimoto, H., Ohara, T., Wankmüller, R., Battye, B., Grano, D., Zuber, A., and Keating, T.: EDGAR-HTAP: a harmonized gridded air pollution emission dataset based on national inventories, Tech. Rep. JRC68434, Publications Office of the European Union, available at: https://doi.org/10.2788/14102 (last access: January 2017), 2000.

Ketterer, C., Zieger, P., Bukowiecki, N., Collaud Coen, M., Maier, O., Ruffieux, D., and Weingartner, E.: Investigation of the Planetary Boundary Layer in the Swiss Alps Using Remote Sensing and In Situ Measurements, Bound.-Lay. Meteorol., 151, 317334, https://doi.org/10.1007/s10546-013-9897-8, 2014

Kotthaus, S., O'Connor, E., Münkel, C., Charlton-Perez, C., Haeffelin, M., Gabey, A. M., and Grimmond, C. S. B.: Recommendations for processing atmospheric attenuated backscatter profiles from Vaisala CL31 ceilometers, Atmos. Meas. Tech., 9, 37693791, https://doi.org/10.5194/amt-9-3769-2016, 2016.

Kurokawa, J., Ohara, T., Morikawa, T., Hanayama, S., JanssensMaenhout, G., Fukui, T., Kawashima, K., and Akimoto, H.: Emissions of air pollutants and greenhouse gases over Asian regions during 2000-2008: Regional Emission inventory in ASia (REAS) version 2, Atmos. Chem. Phys., 13, 11019-11058, https://doi.org/10.5194/acp-13-11019-2013, 2013.

Münkel, C.: Mixing height determination with lidar ceilometers - results from Helsinki Testbed, Meteorol. Z., 16, 451-459, https://doi.org/10.1127/0941-2948/2007/0221, 2007.

Münkel, C. and Roininen, R.: Automatic monitoring of boundary layer structures with ceilometers, Vaisala News 184, 2010.

Münkel, C., Schäfer, K., and Emeis, S.: Adding confidence levels and error bars to mixing layer heights detected by ceilometer, Proc. SPIE, 8177, https://doi.org/10.1117/12.898122, 2011.

Panday, A. K. and Prinn, R. G.: Diurnal cycle of air pollution in the Kathmandu Valley, Nepal: Observations, J. Geophys. Res.Atmos., 114, https://doi.org/10.1029/2008JD009777, 2009.

Panday, A. K., Prinn, R. G., and Schär, C.: Diurnal cycle of air pollution in the Kathmandu Valley, Nepal: 2. Modeling results, J. Geophys. Res.-Atmos., 114, https://doi.org/10.1029/2008JD009808, 2009.

Petzold, A., Ogren, J. A., Fiebig, M., Laj, P., Li, S.-M., Baltensperger, U., Holzer-Popp, T., Kinne, S., Pappalardo, G., Sugimoto, N., Wehrli, C., Wiedensohler, A., and Zhang, X.-Y.: Recommendations for reporting "black carbon" measurements, Atmos. Chem. Phys., 13, 8365-8379, https://doi.org/10.5194/acp13-8365-2013, 2013.

Putero, D., Cristofanelli, P., Marinoni, A., Adhikary, B., Duchi, R., Shrestha, S. D., Verza, G. P., Landi, T. C., Calzolari, F., Busetto, M., Agrillo, G., Biancofiore, F., Di Carlo, P., Panday, A. K., Rupakheti, M., and Bonasoni, P.: Seasonal variation of ozone and black carbon observed at Paknajol, an urban site in the Kathmandu Valley, Nepal, Atmos. Chem. Phys., 15, 13957-13971, https://doi.org/10.5194/acp-15-13957-2015, 2015.

Regmi, R., Kitada, T., and Kurata, G.: Numerical simulation of Late wintertime local flows in Kathmandu Valley, Nepal: Implication for air pollution transport, J. Appl. Meteorol., 42, 404-416, 2003.

Rupakheti, M., Panday, A. K., Lawrence, M. G., Kim, S. W., Sinha, V., Kang, S. C., Naja, M., Park, J. S., Hoor, P., Holben, B.,
Sharma, R. K., Mues, A., Mahata, K. S., Bhardwaj, P., Sarkar, C., Rupakheti, D., Regmi, R. P., and Gustafsson, Ö.: Air pollution in the Himalayan foothills: overview of the SusKat-ABC international air pollution measurement campaign in Nepal, Atmos. Chem. Phys., in preparation, 2017

Sandeep, P., Saradhi, I. V., and Pandit, G. G.: Seasonal variation of black carbon in fine particulate matter (PM 2.5) at the tropical coastal city of Mumbai, India, Bulletin of Environmental Contamination and Toxicology, 91, 605-610, https://doi.org/10.1007/s00128-013-1108-2, 2013.

Sarkar, C., Sinha, V., Kumar, V., Rupakheti, M., Panday, A., Mahata, K. S., Rupakheti, D., Kathayat, B., and Lawrence, M. G.: Overview of VOC emissions and chemistry from PTR-TOFMS measurements during the SusKat-ABC campaign: high acetaldehyde, isoprene and isocyanic acid in wintertime air of the Kathmandu Valley, Atmos. Chem. Phys., 16, 3979-4003, https://doi.org/10.5194/acp-16-3979-2016, 2016.

Sharma, R. K., Bhattarai, B. K., Sapkota, B., Gewali, M. B., and Kjeldstad, B.: Variation of Black Carbon Aerosols on Six Continuous Strike Days of Kathmandu Valley: A Case Study, Journal of the Institute of Engineering, 8, 105-113, 2012.

Shrestha, A. B., Wake, C. P., Dibb, J. E., Mayewski, P. A., Whitlow, S. I., Carmichael, G. R., and Ferm, M.: Seasonal variations in aerosol concentrations and compositions in the Nepal Himalaya, Atmos. Environ., 34, 3349-3363, https://doi.org/10.1016/S13522310(99)00366-0, 2000.

Shrestha, R. K., Gallagher, M. W., and Connolly, P. J.: Diurnal and seasonal variations of meteorology and aerosol concentrations in the foothills of the nepal himalayas (Nagarkot: 1,900 m asl), Asia-Pacific Journal of Atmospheric Sciences, 52, 63-75, 2016.

Shrestha, S., Shrestha, S., Maharjan, S., and Regmi, R.: Boundary Layer Characteristics over Aindanda Low-Mountain Pass of Kathmandu Valley, Nepal, Journal of Institute of Science and Technology, 20, 22-30, 2015.

Singh, N., Solanki, R., Ojha, N., Janssen, R. H. H., Pozzer, A., and Dhaka, S. K.: Boundary layer evolution over the central Himalayas from radio wind profiler and model simulations, Atmos. Chem. Phys., 16, 10559-10572, https://doi.org/10.5194/acp-1610559-2016, 2016.

Steyn, D., Baldi, M., and Hoff, R.: The detection of mixed layer depth and entrainment zone thickness from lidar backscatter profiles, J. Atmos. Ocean. Tech., 16, 953-959, 1999.

Stull, R. B.: An introduction to boundary layer meteorology, Kluwer Academic Press, https://doi.org/10.1007/978-94-0093027-8, 1988.

Sturges, H. A.: The choice of a class interval, J. Am. Stat. Assoc., 21, 65-66, 1926.

Tang, G., Zhu, X., Hu, B., Xin, J., Wang, L., Münkel, C., Mao, G., and Wang, Y.: Impact of emission controls on air quality in Beijing during APEC 2014: lidar ceilometer observations, Atmos. Chem. Phys., 15, 12667-12680, https://doi.org/10.5194/acp-1512667-2015, 2015.

Tiwari, S., Bisht, D. S., Srivastava, A. K., and Gustafsson, Ö.: Simultaneous measurements of black carbon and PM2.5, CO, and NOx variability at a locally polluted urban location in India, Nat. Hazards, 75, 813-829, https://doi.org/10.1007/s11069-0141351-9, 2015.

Wagner, P.: Analyse von biogenem und anthropogenem Isopren und seiner Bedeutung als Ozonvorläufersubstanz in der Stadtatmo- 
sphäre, Ph.D. thesis, Hohenwarsleben, zugl. Duisburg, Essen, Univ., Diss., 2014.

Wiegner, M., Madonna, F., Binietoglou, I., Forkel, R., Gasteiger, J., Geiß, A., Pappalardo, G., Schäfer, K., and Thomas, W.: What is the benefit of ceilometers for aerosol remote sensing? An answer from EARLINET, Atmos. Meas. Tech., 7, 1979-1997, https://doi.org/10.5194/amt-7-1979-2014, 2014.
Zhang, Q., Streets, D. G., Carmichael, G. R., He, K. B., Huo, H., Kannari, A., Klimont, Z., Park, I. S., Reddy, S., Fu, J. S., Chen, D., Duan, L., Lei, Y., Wang, L. T., and Yao, Z. L.: Asian emissions in 2006 for the NASA INTEX-B mission, Atmos. Chem. Phys., 9, 5131-5153, https://doi.org/10.5194/acp-9-5131-2009, 2009. 